\title{
Effect of chemistry on martensitic phase transformation kinetics and resulting properties of additively manufactured stainless steel
}

\author{
Zhuqing Wang ${ }^{1}$ and Allison M. Beese ${ }^{1^{*}}$ \\ ${ }^{1}$ Department of Materials Science and Engineering, \\ Pennsylvania State University \\ University Park, PA 16802 \\ Corresponding author: amb961@psu.edu
}

\begin{abstract}
Here we investigate the effect of chemistry, including initial powder chemistry and spatial chemical variations due to vaporization during fabrication, on strain-induced martensitic phase transformation in 304L stainless steel components fabricated by directed energy deposition (DED) additive manufacturing (AM). The austenite stability was altered by mixing pre-alloyed 304L stainless steel powder with Fe powder, which promoted martensitic phase transformation and resulted in an increase in ultimate tensile strength and elongation to failure over pure 304L walls deposited by DED AM. The chemical composition variation with position, due to spatial variations in thermal history, was quantified, showing that austenite stabilizing elements $\mathrm{Cr}$, Mn, and $\mathrm{Ni}$ were preferentially vaporized during deposition. We present a martensitic transformation kinetics equation that describes the evolution of martensite volume fraction with respect to plastic strain as a function of chemistry. This allows for the prediction of strain-induced martensite evolution as a function of strain, nominal chemistry, and heterogeneous chemistry due to vaporization within additively manufactured components.
\end{abstract}

Key words: Additive manufacturing; Austenitic stainless steels; Austenite-to-martensite phase transformation; Elemental vaporization 


\section{Introduction}

In laser-based, powder-based directed energy deposition (DED) additive manufacturing (AM), 3D components are fabricated through a repetitive process of generating a melt pool on a substrate or previous layer with a laser and delivering powder feedstock directly to the melt pool through nozzles. As the laser beam travels, the melt pool rapidly solidifies and fuses to the layer below [1-3]. Each location in the build undergoes rapid heating and cooling cycles with the addition of new layers. The complex thermal history results in heterogeneous and anisotropic microstructures and mechanical properties in additively manufactured components that are different from traditionally wrought materials [4-6].

In this work, the microstructure and uniaxial mechanical properties of AISI type 304L austenitic stainless steel (SS304L) fabricated by DED were studied. When austenitic stainless steels are plastically deformed, the relatively soft austenitic phase has the potential to transform to a harder martensitic phase, which forms at nucleation sites created by dislocation interactions. This deformation-induced, or 'strain-induced,' phase transformation, often referred to as the TRansformation Induced Plasticity (TRIP) effect, results in an increase in the macroscopic strain hardening rate and a crystallographic volume expansion of 2-4 vol.\% [7-17]. The strain-induced martensitic phase transformation in this study is fundamentally different from thermally-induced or stress-induced martensitic phase transformation, in which austenite-to-martensite phase transformation occurs in the elastic region of austenite and martensite forms at pre-existing nucleation sites within the austenite matrix $[9,11]$. The rate of strain-induced martensitic phase transformation with respect to increment in plastic strain is influenced by the chemical composition, stress state, strain, strain rate, and temperature $[8,10,11]$. 
The ability for an austenitic stainless steel to undergo strain-induced phase transformation depends on the material's chemical composition, as this affects the stacking fault energy (SFE) of austenite [18]. The addition of alloying elements that increase the SFE of austenite, decrease the width of stacking faults, promoting cross-slip instead, and increase the stability of austenite. A stacking fault in face-centered cubic (fcc) austenite changes the stacking sequence of the $\{111\}$ planes from $\mathrm{ABCABC}$ to $\mathrm{ABAB}$, which is the stacking sequence of a hexagon closepacked (hcp) structure [18]. Therefore, stacking faults in austenite act as nucleation sites for hcp $\varepsilon$-martensite, which is an intermediate phase for the formation of body-centered cubic (bcc) strain-induced $\alpha$ ' martensite from austenite [9,19]. Consequently, a decrease in the width of stacking faults suppresses the generation of energetically favorable nucleation sites for straininduced martensite [18]. Talonen and Hänninen [20] studied strain-induced martensitic phase transformation in 304 stainless steel and 301LN stainless steel, showing that the rate of phase transformation with respect to plastic strain depends on composition and temperature. Angel [8] investigated the effect of chemistry on strain-induced martensitic phase transformation in austenitic stainless steels and showed that carbon, nitrogen, chromium, nickel, silicon, manganese, and molybdenum increased austenite stability, and therefore, decreased the straininduced martensite finish temperature. Tomimura et al. [21] found that the amount of straininduced martensite increased with the increase in the weight fraction of chromium and nickel in cold rolled austenitic stainless steels.

The elemental composition of additively manufactured components depends on the chemistry of the initial powder, any absorption of oxygen, nitrogen, or argon from the chamber environment during fabrication, or elemental vaporization during deposition, and can vary with location within components [2,22-24]. A previous study by the authors on SS304L components 
produced by DED showed that when using pre-alloyed SS304L powder gas atomized in nitrogen, the 4 wt.\% increase in N with respect to traditionally annealed SS304L, stabilized the austenite, resulting in no phase transformation in the additively manufactured materials, while phase transformation was apparent in the annealed SS304L with plastic deformation [2]. Rafi et al. [24] studied the influence of build environment on microstructure and mechanical properties of additively manufactured 17-4 PH stainless steel. They found that the components contained a mixture of retained austenite (50-75 vol.\%) and thermally-induced martensite (25-50 vol.\%) when built in nitrogen, and mostly thermally-induced martensite (92 vol.\%) when built in argon. The component built in nitrogen had a higher fracture toughness than the component built in argon due to the strain-induced austenite-to-martensite phase transformation present in the former.

In addition to depending on the powder composition and build environment, the chemical composition of components made by AM can vary from the initial powder composition, and as a function of position, if volatile elements vaporize from the molten pool during deposition [25]. The amount of elemental depletion is affected by the temperature of the molten pool, which is dependent on the temperature of the layer onto which new material is being added, as well as the energy input [26]. The most volatile elements in SS304 are $\mathrm{Cr}, \mathrm{Ni}$, and $\mathrm{Mn}$ [27], all of which are austenite stabilizers; therefore, depletion of these elements should impact the propensity for strain-induced martensitic phase transformation.

The strain-induced martensitic phase transformation in traditionally annealed or rolled austenitic stainless steels has been well studied [7-15], but little is known about the martensitic phase transformation kinetics in additively manufactured stainless steels. The aim of this work was to investigate the effect of initial powder chemistry, and spatial chemical composition 
changes due to vaporization, on the strain-induced martensitic phase transformation in SS304L

made by DED. The chemistry as a function of location and starting composition was quantified, and the resulting phase transformation was characterized during uniaxial tension tests using in situ magnetic permeability measurements confirmed with time of flight neutron diffraction. A phase transformation kinetics equation that describes the amount of strain-induced martensite as a function of plastic strain, and in which the parameters depend on chemistry through the martensite finish temperature, is proposed and calibrated for the additively manufactured 304L stainless steel.

\section{Experimental}

Two geometrically similar walls measuring 140 mm long x $104 \mathrm{~mm}$ tall x $14 \mathrm{~mm}$ thick were deposited on annealed 304L stainless steel substrates (ASTM A479 standard [28]) using laser based DED with powder feedstock. During the deposition of each wall, the substrate was clamped with 4 bolts to an aluminum fixture, and a thermocouple was attached to the bottom of the stainless steel substrate to measure the temperature during the build process. In order to isolate the effect of powder chemistry on microstructure and mechanical properties, the two walls were fabricated using the same processing parameters, but with different powder compositions by mixing pre-alloyed SS304L powder and pure Fe powder as shown in Table 1. The pre-alloyed SS304L powder was gas atomized in nitrogen (Carpenter Powder Products, Corp.), and had the elemental composition given in Table 2. The Fe powder was hydrogen reduced (Atlantic Equipment Engineers) with a purity of 99.8\%. The SS304L powder and Fe 
powder were sieved to $+325 /-100$ mesh, resulting in a powder diameter range of $45 \mu \mathrm{m}$ to 145 $\mu \mathrm{m}$.

To mix the powders, the pre-alloyed SS304L powder and pure Fe powder were combined in a sealed container filled with argon and put in a Type T2C Turbula mixer (Willy A. Bachofen AG Maschinenfabrik, Switzerland), which moved in three dimensions for 1 hour to ensure random mixing of the two powder types.

One wall was built using a mixture of 80 vol.\% SS304L pre-alloyed powder and 20 vol. $\%$ Fe powder, referred as the $80 \%$ SS304L wall; the other wall was built using a mixture of 90 vol.\% SS304L pre-alloyed powder and 10 vol.\% Fe powder, referred as the 90\% SS304L wall. EDS mapping of different regions from the $80 \%$ and $90 \%$ SS304L walls showed no elemental segregation (Figure 1), which was indicative of sufficient mixing of the powders. A custom-built DED system with an ytterbium fiber laser (IPG Photonics ${ }^{\circledR}$ YLR-12000L) operating at a wavelength from 1070 to $1080 \mathrm{~nm}$ was used to fabricate the components. The components were deposited in a chamber purged with ultra-high purity argon to minimize oxygen contamination. Pre-mixed powder was delivered by a four-nozzle system in which the nozzles were about $10 \mathrm{~mm}$ above the substrates, and a laser spot size of $4 \mathrm{~mm}$ in diameter was used in a defocused condition.

Uniaxial tension specimens were extracted from different orientations and locations from the $80 \%$ and $90 \%$ SS304L walls by wire electrical discharge machining (EDM) with gauge dimensions of $21.5 \mathrm{~mm}$ long x $4 \mathrm{~mm}$ wide x $1.5 \mathrm{~mm}$ thick, adhering to ASTM E8 [29]. Specimens whose tensile axes were perpendicular to the build direction, and parallel to the length of the wall, are denoted as longitudinal specimens, whereas specimens whose tensile axes were parallel to the build direction are denoted as transverse specimens. As a comparison, 
tensile specimens were also cut from the annealed SS304L substrate and a wall built from 100 vol.\% pre-alloyed SS304L powder by DED (referred as 100\% SS304L) using the processing parameters given in Table 1 [2].

X-ray computed tomography $(\mathrm{CT})$ is a nondestructive technique that can be used to detect internal features in bulk materials. Here, an X-ray CT system (General Electric phoenix v|tome|x m) equipped with a $300 \mathrm{kV}$ microfocus X-ray tube and a $200 \mu \mathrm{m}$-pitch GE DXR250 flat panel detector, was used to detect the size, shape, and location of internal defects in two representative tensile specimens from the $80 \%$ SS304L wall before mechanical testing. The scans were performed using a beam power of $200 \mathrm{kV}$, a current of $87 \mu \mathrm{A}$, a voxel size of 17.5 $\mu \mathrm{m}$, a scan time of 20 minutes per sample, and a total of 1200 projections per scan. The voxel size used allows for the detection of pores $35 \mu \mathrm{m}$ or larger in diameter [2,30]. The acquired scans were analyzed using VGStudio Max 2.2 visualization and analysis software.

The amount of strain-induced austenite-to-martensite phase transformation in the SS304L samples was determined through magnetic permeability measurements using a feritescope (Fisher Feritescope FMP 30). The as-built SS304L consists of paramagnetic austenite, ferromagnetic ferrite (under 2 vol. \%), and potentially ferromagnetic martensite. Therefore, magnetic permeability measurements can be used to detect the presence of martensite and ferrite in specimens, but cannot differentiate between these two phases [31-34]. During plastic deformation, the volume fraction of ferrite remains constant, but austenite may transform to martensite [10,35-37], resulting in an increase in the magnetic permeability. However, due to negative magnetostriction, or the Villari effect, the magnetic permeability of ferromagnetic materials decreases when subjected to tension as a result of rotation and re-orientation of magnetic domains in ferromagnetic materials with applied force $[33,38]$. In order to reduce the 
impact of the Villari effect on magnetic permeability measurements, specimens must be unloaded during the measurements so that they are macroscopically stress-free. In this study, the specimens were loaded to $7 \%$ engineering strain, unloaded to measure the magnetic permeability in macroscopically stress-free samples, and then loaded to another increment of $7 \%$ engineering strain before unloading and taking the next set of measurements.

Both monotonic and periodic loading/unloading uniaxial tensile tests were conducted using an electromechanical testing frame (Instron 4202, $10 \mathrm{kN}$ load cell) at a strain rate of $1.2 \times 10^{-3} \mathrm{~s}^{-1}$. Strains were computed using digital image correlation (DIC, Vic2D, Correlated Solutions). In this technique, the gauge region of each sample was painted with a white background, with a black speckle pattern on top. A digital camera (Point Grey GRAS-50S5MC) recorded images of the deformed gauge region using a pixel size of $90 \mu \mathrm{m}$ during each test. The evolving surface deformation fields were computed by applying a cubic B-spline interpolation algorithm to the images in the Vic2D software. A subset size of 21 pixels with a step size of 5 pixels was used, resulting in a virtual strain gauge length of 56 pixels or $5 \mathrm{~mm}$ [39]. A $21 \mathrm{~mm}$-long virtual extensometer was used to calculate axial strain in the gauge region of each specimen. For periodic loading/unloading tensile tests, a feritescope probe was placed perpendicular to the gauge of each specimen, and kept in direct contact with the specimen throughout the tensile test to record the evolution of martensite content. The martensite volume fraction, $c$, can be estimated from the feritescope output, $S_{F e}$, using the following equation:

$$
c=k S_{F e}
$$

where $k$ is the conversion factor from vol. $\%$ ferrite to vol.\% martensite.

The conversion factor, $k$, was determined by measuring the martensite content in deformed regions of annealed 304L stainless steel after plastic deformation. Time of flight 
neutron diffraction was performed at three points with different amounts of plastic deformation using the VULCAN instrument at the Spallation Neutron Source at Oak Ridge National Laboratory [40]. A detailed description of VULCAN can be found in [41,42]. The martensite volume fractions at the three points with different plastic strain levels were determined from the diffraction patterns and compared with the feritescope readings to compute the conversion factor, $k$. A schematic of the neutron diffraction experimental setup is given in Figure 2. The two detector banks recorded diffraction patterns from grains that had $h k l$-specific lattice planes normal to the length and thickness directions. The peak positions and integrated peak intensities of the diffraction peaks from austenite $(\gamma, \mathrm{fcc})$ and martensite $\left(\alpha^{\prime}\right.$, bcc $)$ were computed using VDRIVE software in order to calculate the phase fractions of austenite and martensite [43].

The internal standard method, described below, was used to determine the volume fraction of austenite and martensite in SS304L. The intensity of an $h k l$ peak in austenite $\left(I_{h k l, \gamma}\right)$ is expressed as [44]:

$$
I_{h k l, \gamma}=\frac{K_{e} K_{h k l, \gamma} V_{\gamma}}{\left(\frac{\mu}{\rho}\right)_{m}}
$$

where $K_{e}$ is an experimental system constant determined by the incident beam intensity and wavelength, diffractometer radius, and diffraction angle, $V_{\gamma}$ is the vol. $\%$ of austenite, $\left(\frac{\mu}{\rho}\right)_{m}$ is the mass absorption coefficient in SS304L, and $K_{h k l, \gamma}$ is a constant for an $h k l$ peak in austenite, given as:

$$
K_{h k l, \gamma}=\frac{M_{h k l, \gamma}}{v_{\gamma}{ }^{2}}\left|F_{h k l, \gamma}\right|^{2}\left(d_{h k l, \gamma}{ }^{4} \sin \theta\right)
$$

where $M_{h k l, \gamma}$ is the multiplicity of an $h k l$ peak of austenite, $v_{\gamma}$ is the volume of a unit cell of austenite, $F_{h k l, \gamma}$ is the structure factor of an $h k l$ peak of austenite, $d_{h k l, \gamma}$ is an $h k l$-specific lattice 
spacing in austenite, $\theta$ is the diffraction angle $\left(45^{\circ}\right.$ here $)$, and $d_{h k l, \gamma}{ }^{4} \sin \theta$ is the Lorentz factor in neutron diffraction.

Therefore, we have:

$$
\frac{V_{\gamma}}{V_{\alpha \prime}}=\frac{I_{h k l, \gamma} K_{h k l, \alpha \prime}}{I_{h k l, \alpha \prime} K_{h k l, \gamma}}
$$

where $V_{\alpha}$, is the vol. $\%$ of martensite, $K_{h k l, \alpha}$, is a constant for an $h k l$ peak in martensite, $I_{h k l, \alpha}$, is an $h k l$ peak intensity in martensite. The peak intensity and d-spacing are determined from neutron diffraction data.

The uncertainty in martensite content measured by neutron diffraction $\left(u_{V \alpha}\right)$ is due to the uncertainty in the peak intensity measurement. Using a propagation of uncertainty approach, this uncertainty is given by:

$$
u_{V \alpha \prime}=\frac{\left[\left(100 K_{h k l, \gamma} \delta I_{h k l, \alpha^{\prime}}\right)^{2}+\left(K_{h k l, \gamma} \delta I_{h k l, \alpha^{\prime}}\right)^{2}+\left(K_{h k l, \alpha \prime} \delta I_{h k l, \gamma}\right)^{2}\right]^{\frac{1}{2}}}{I_{h k l, \alpha \prime} K_{h k l, \gamma+I_{h k l, \gamma} K_{h k l, \alpha \prime}}}
$$

where $\delta I_{h k l, \alpha}$, is the uncertainty in the $I_{h k l, \alpha}$, measurement, and $\delta I_{h k l, \gamma}$ is the uncertainty in the $I_{h k l, \gamma}$ measurement.

The Vickers microhardness was measured along the height of the $80 \%$ and $90 \%$ SS304L walls using a load of $200 \mathrm{~g}$ and a dwell time of $15 \mathrm{~s}$ (Leco MHT Series 200). In each wall, the indentations were conducted at 10 heights, which started at $10 \mathrm{~mm}$ from the top of the wall, and were spaced $7 \mathrm{~mm}$ apart down the wall. A minimum of five measurements were taken at each height.

The microstructures of specimens were characterized using an optical microscope (OM; Keyence VHX-2000) and electron backscatter diffraction (EBSD; Oxford Nordlys Max2). The specimens were polished using $0.05 \mu \mathrm{m}$ colloidal silica for observation of lack-of-fusion pores in $\mathrm{OM}$ and identification of phases by EBSD. 
The elemental compositions of as-built material from different locations in the $80 \%$ and 90\% SS304L walls were measured (Element Materials Technology, Newtown, PA) as shown in Table 2. The carbon and sulfur contents were determined by combustion testing, the nitrogen content was measured using inert gas fusion (ASTM E1019 [45]), and the remaining elements were determined by optical emission spectrometry (ASTM E1086 [46]).

\section{Results and discussion}

\subsection{Overview}

Representative engineering stress-strain curves of longitudinal and transverse specimens from the $80 \%, 90 \%$, and 100\% SS304L walls, and annealed SS304L substrate are given in Figure 3, while uniaxial mechanical properties for samples from the three walls and substrate are given in Table 3. Specimens from the 100\% SS304L wall had a lower ultimate tensile strength and elongation to failure compared to the annealed SS304L, while the ultimate tensile strengths and elongations to failure of specimens from the $90 \%$ and $80 \%$ SS304L were comparable to those of the annealed SS304L.

Among the three additively manufactured walls, for specimens cut from the same orientation, there was no clear trend in yield strength, but the ultimate tensile strength increased with increasing Fe powder. The elongations to failure in the $80 \%$ and $90 \%$ SS304L walls were higher than those in the $100 \%$ SS304L wall. For specimens cut from the $100 \%$ and $90 \%$ SS304L walls, there was no clear trend in yield strength and ultimate tensile strength with respect to direction, which agrees with the results in [2]. However, the transverse specimens from the $80 \%$ SS304L wall had significantly lower elongations to failure, ultimate tensile strengths, and $\Delta \mathrm{FN}$ than the longitudinal specimens in the same wall. This is because these samples had lack-of- 
fusion pores (e.g., [4], about 0.2 vol.\%) as verified by X-ray CT analysis. These pores were oriented with their long axes perpendicular to the build direction. The build direction corresponds to the tensile axes in transverse samples as shown in Figure 4. The sharp corners of these lack-of-fusion pores serve as stress concentration sites when tension is applied in the build direction. The reduction in ductility that results from the presence of these internal defects reduces the span of the test, and correspondingly, the ultimate tensile strength and amount of strain-induced martensite were limited in the build direction when lack-of-fusion porosity was present.

Regarding heterogeneity of properties, in longitudinal specimens from the 100\% SS304L wall, the yield and ultimate tensile strengths decreased as the distance from the substrate increased, as shown in Figures 5a and 5b. During additive manufacturing, with the deposition of new layers, the dissipation of heat through the wall and substrate decreases due to the added energy and increased temperature of the wall. Therefore, the temperature of the top layer onto which a new layer will be deposited, as well as the molten pool in that layer, increases with height $[26,47,48]$.

The evolution of the temperature of the top layer as a function of height during deposition was approximated using a simplified finite element simulation (Abaqus 6.14 [49]). Here, we considered heat conduction in the additively manufactured SS304L wall, SS304L substrate, and aluminum fixture to which the substrate was clamped. The bottom of the $101 \mathrm{~mm}$ tall aluminum fixture was approximated to be at room temperature $\left(25^{\circ} \mathrm{C}\right)$ and the entire top surface of the build was assumed to be at a uniform to-be-determined temperature. The thermal contact conductance between the SS304L substrate and aluminum depends on the contact pressure [50]. Assuming that each of the 4 clamping bolts applied approximately $2 \mathrm{kN}$ (corresponding to hand 
tightening of the bolts [51]) of force results in a thermal contact conductance between the substrate and fixture of $1000 \mathrm{~W} / \mathrm{m}^{2} / \mathrm{K}$ [52]. The other thermal properties used in the simulations are given in Table 4. The computed temperature of the top layer of the build, as a function of build height, that results in the temperature measured experimentally by the thermocouple at the bottom of the substrate is given in Figure 6. This analysis shows that the temperature of the top layer, and therefore, that of the molten pool, increases with build height.

The increase in temperature and decrease in cooling rate with height allow for grain coarsening and result in a decrease in yield and ultimate tensile strengths with height in the $100 \%$ SS304L wall. In longitudinal specimens from the 80\% and 90\% SS304L walls, the yield strength was almost constant as a function of position (Figure 5a) due to notable scatter. The ultimate tensile strength decreased with height in the $80 \%$ SS304L wall and increased with height in the 90\% SS304L walls, as shown in Figure 5b, which is likely due to the effect of local chemistry on martensitic transformation as will be discussed in Sections 3.2 and 3.3.

The microhardness was measured as a function of height in the $80 \%$ and $90 \%$ SS304L walls. In both walls, there was no clear trend in hardness with respect to location. The average hardness in the $80 \%$ SS304L wall was $198 \pm 14 \mathrm{HV}$, which is comparable to the average hardness in the $90 \%$ SS304L wall of $203 \pm 13 \mathrm{HV}$.

\subsection{Effect of powder chemistry on microstructure and mechanical properties}

The higher ultimate tensile strength and ductility of specimens from the $80 \%$ and $90 \%$ SS304L walls compared to the $100 \%$ wall resulted from the microstructural phase transformation from austenite to martensite during deformation, which was verified by magnetic permeability measurements. In this study, we use the ferrite number $(\mathrm{FN})$ as the measurement unit for the 
amount of ferromagnetic material. FN is a standard unit used in welded austenitic stainless steels to quantify ferrite content $[53,54]$. The feritescope measures the magnetic permeability of a finite volume of material, roughly equivalent to a cylinder of $2 \mathrm{~mm}$ in depth and $4 \mathrm{~mm}$ in diameter [55]. If the sample thins below $2 \mathrm{~mm}$ or the sample's width decreases below $4 \mathrm{~mm}$, the output signal needs to be corrected for the reduced volume being measured. Thus, the corrected $\mathrm{FN}\left(S_{F N, c}\right)$ of a sample is given by:

$$
S_{F N, c}=S_{F N, m} a
$$

where $a$ is a thickness correction factor, $b$ is a width correction factor [33,55], and $S_{F N, m}$ is the measured FN.

The magnetic permeability of the gauge region in each tensile specimen was measured before loading and after plastic deformation for some samples, and in situ during mechanical tests for others. Table 3 shows the increase in corrected FN in deformed specimens compared to their undeformed FN values:

$$
\Delta \mathrm{FN}=\mathrm{FN}_{\mathrm{t}}-\mathrm{FN}_{0}
$$

where $\mathrm{FN}_{\mathrm{t}}$ is the $\mathrm{FN}$ at a given deformation, and $\mathrm{FN}_{0}$ is the initial $\mathrm{FN}$ in the undeformed sample. There was a significant increase in FN in specimens from the 80\% and 90\% SS304L walls and the annealed SS304L substrate, indicating the presence of strain-induced martensitic phase transformation. The increase in FN after deforming specimens from the 100\% SS304L wall was on the same order of the feritescope resolution (about 1-2 FN), indicating that there was no detectable phase transformation in specimens from this wall.

The martensitic phase transformation in the $80 \%$ and $90 \%$ SS304L walls was also confirmed by EBSD analysis. Both ferrite and strain-induced martensite have body-centered cubic crystal structures, while austenite is face-centered cubic. Therefore, during plastic 
deformation, any increase in the volume fraction of the bcc phase is indicative of martensitic phase transformation. Figure 7 shows EBSD phase maps in a specimen from the $90 \%$ SS304L wall. There was a 46 area $\%$ increase in the bcc phase content in the deformed gauge region compared with the undeformed grip region. This corresponds to an increase of $26 \mathrm{FN}$ when assuming that area $\%$ is approximately equal to vol. $\%$ and this volume fraction is converted to $\Delta \mathrm{FN}$ using the conversion factor that will be discussed in Section 3.4. The computed $\Delta \mathrm{FN}$ from EBSD analysis agreed with the feritescope $\triangle \mathrm{FN}$ reading of 25 for this sample. Together, these results confirm the strain-induced martensitic phase transformation in the 90\% SS304L wall.

Strain-induced martensitic phase transformation occurs between the start temperature of strain-induced martensitic phase transformation, $\mathrm{M}_{\mathrm{s}}{ }^{\sigma}$, and the martensite finish temperature, $\mathbf{M}_{\mathrm{d}}$. The $\mathrm{M}_{\mathrm{s}}{ }^{\sigma}$ and $\mathrm{M}_{\mathrm{d}}$ temperatures depend on the chemical composition, as this affects the stability of austenite. Above $\mathrm{M}_{\mathrm{d}}$, austenite is stable and will not transform to martensite. Between $\mathrm{M}_{\mathrm{s}}{ }^{\sigma}$ and $\mathrm{M}_{\mathrm{d}}$, metastable austenite has the potential to transform to martensite with plastic deformation, as the dislocations and their interactions create nucleation sites for martensite $[9,10,56]$. As it is difficult to measure $\mathrm{M}_{\mathrm{d}}$, Angel proposed the following widely used empirical expression for an $\mathrm{M}_{\mathrm{d} 30}$ temperature, which is defined as the temperature at which $50 \mathrm{vol} . \%$ of austenite transforms to martensite at a true strain of $30 \%$, and is given by [8]:

$$
M_{d 30}\left({ }^{\circ} \mathrm{C}\right)=413-463(C+N)-9.2 S i-8.1 M n-13.7-9.5 N i-18.5 M o
$$

where the elemental compositions are given in weight percent. The $M_{d 30}$ temperature can be interpreted as a pseudo-upper bound for martensitic transformation.

The presence or absence of strain-induced martensitic transformation can be explained by the computed $M_{d 30}$. If the $M_{d 30}$ of an austenitic stainless steel is below room temperature, which is the temperature that all mechanical tests were performed in this study, it is unlikely that strain- 
induced phase transformation will occur. However, if the $\mathrm{M}_{\mathrm{d} 30}$ is above room temperature, it is possible that the strain-induced phase transformation will occur. Based on the chemical analysis results in Table 2 and Eqn. (8), the $\mathrm{M}_{\mathrm{d} 30}$ temperatures computed of specimens from different locations from the $80 \%$ and $90 \%$ SS304L walls were above $25{ }^{\circ} \mathrm{C}$. Thus, strain-induced martensitic phase transformation was anticipated in those walls at room temperature. The $M_{\mathrm{d} 30}$ temperature computed for the $100 \% \mathrm{SS} 304 \mathrm{~L}$ wall was $-3.6^{\circ} \mathrm{C}$, indicating that strain-induced phase transformation was unlikely to occur in the 100\% SS304L material [2]. Mixing the prealloyed SS304L powder with Fe powder reduced the relative wt.\% of austenite stabilizers ( $\mathrm{Si}$, $\mathrm{Mn}, \mathrm{Cr}$, and $\mathrm{Ni}$ ), which resulted in higher $\mathrm{M}_{\mathrm{d} 30}$ temperatures in the $80 \%$ and $90 \% \mathrm{SS} 304 \mathrm{~L}$ walls compared to the $100 \%$ SS304L wall. Therefore, the austenite was metastable and transformed to martensite with plastic deformation in the $80 \%$ and $90 \%$ SS304L walls. Since martensite has a higher flow stress than austenite [57], this evolution of microstructure, with increasing martensite and decreasing austenite with plastic strain in the $80 \%$ and $90 \%$ SS304L walls increased the strain hardening rate, therefore stabilizing the neck and increasing elongation to failure, and also increasing the ultimate tensile strength over the 100\% SS304L wall as shown in Table 3.

The propensity for strain-induced martensitic transformation can also be estimated by computing the stacking fault energy (SFE) of the material. Decreasing SFE in austenitic stainless steels results in wider stacking faults, which are nucleation sites for hcp $\varepsilon$ martensite, and which transform to $\alpha^{\prime}$ martensite with plastic deformation. It is reported that austenite has the potential to transform to strain-induced martensite when the SFE is less than approximately $20 \mathrm{~mJ} / \mathrm{m}^{2}$ [58,59]. Olson and Cohen proposed a thermodynamic model to calculate the SFE for austenitic stainless steels, which is given as [60]: 


$$
\gamma_{\mathrm{SFE}}=2 \rho \Delta \mathrm{G}^{\gamma \rightarrow \varepsilon}+2 \sigma
$$

where $\gamma_{\mathrm{SFE}}$ is the stacking fault energy, $\sigma$ is the surface energy, $\Delta \mathrm{G}^{\gamma \rightarrow \varepsilon}$ is the Gibbs energy difference between $\gamma$ austenite and $\varepsilon$ martensite, and $\rho$ is the molar surface density of $\{111\}$ planes of austenite, defined as:

$$
\rho=\frac{4}{\sqrt{3} \mathrm{a}^{2} \mathrm{~N}_{\mathrm{A}}}
$$

where $a$ is the lattice parameter of austenite, and $\mathrm{N}_{\mathrm{A}}$ is Avogadro's constant. The values of the constants used in the SFE calculation here are given in Table 5.

The change in Gibbs energy for the phase transformation from $\gamma$-austenite to $\varepsilon$ martensite, $\Delta \mathrm{G}^{\gamma \rightarrow \varepsilon}$, is expressed as $[59,61,62]$ :

$$
\Delta \mathrm{G}^{\gamma \rightarrow \varepsilon}=\sum_{\mathrm{i}} \mathrm{x}_{\mathrm{i}} \Delta \mathrm{G}_{\mathrm{i}}^{\gamma \rightarrow \varepsilon}+\sum_{\mathrm{ij}} \mathrm{x}_{\mathrm{i}} \mathrm{x}_{\mathrm{j}} \Omega_{\mathrm{ij}}^{\gamma \rightarrow \varepsilon}+\Delta \mathrm{G}_{\mathrm{mg}}^{\gamma \rightarrow \varepsilon}+\Delta \mathrm{G}_{\mathrm{int}}^{\gamma \rightarrow \varepsilon}
$$

where $\mathrm{x}_{\mathrm{i}, \mathrm{j}}$ is the molar fraction of pure elements, $\Omega_{\mathrm{ij}}^{\gamma \rightarrow \varepsilon} \mathrm{is}$ the excess free energy, $\Delta \mathrm{G}_{\mathrm{i}}^{\gamma \rightarrow \varepsilon}$ is the chemical contributions of each element to the change in Gibbs energy, $\Delta \mathrm{G}_{\mathrm{mg}}^{\gamma \rightarrow \varepsilon}$ is the magnetic contribution, and $\Delta \mathrm{G}_{\mathrm{int}}^{\gamma \rightarrow \varepsilon}$ is the contribution of nitrogen segregation

The parameters $\Delta \mathrm{G}_{\mathrm{i}}^{\gamma \rightarrow \varepsilon}, \Omega_{\mathrm{ij}}^{\gamma \rightarrow \varepsilon}, \Delta \mathrm{G}_{\mathrm{mg}}^{\gamma \rightarrow \varepsilon}$, and $\Delta \mathrm{G}_{\mathrm{int}}^{\gamma \rightarrow \varepsilon}$ in Eqn. (11) are given in [59,61,62] and the molar fraction of each element is calculated based on Table 2. The SFE of the 100\%, 90\%, and 80\% SS304L walls at room temperature can be calculated using Eqns. (9) - (11), with the resulting values given in Table 5. A decrease in SFE results in a decrease in austenite stability and an increase in the potential for strain-induced martensitic phase transformation. As shown in Table 5, the SFE from high to low, or the potential for strain-induced martensitic phase transformation from low to high in the additively manufactured walls is: $100 \%, 90 \%$, then $80 \%$ 
SS304L. This trend matches that of the computed $\mathrm{M}_{\mathrm{d} 30}$ temperatures in Table 2. Note that the computed SFEs of all SS304L walls are higher than $20 \mathrm{~mJ} / \mathrm{m}^{2}$, which is likely due to the fact that this model describes the idealized SFE of an infinite stacking fault without defects, while the SFE of actual materials is affected by grain size, dislocations, and point defects [61]. Studies by Moallemi et al.[58] and Curtze et al.[61] investigated SFE of austenitic stainless steels using the thermodynamic model in Eqns. (9) - (11) and found that the thermodynamic model overestimated SFEs compared to experimental results.

\subsection{Effect of location on microstructure and mechanical properties}

In the $80 \%$ and $90 \%$ SS304L walls, the ultimate tensile strength and $\Delta \mathrm{FN}$ were found to be location-dependent, as shown in Figures 5b and 5c, respectively. In the 90\% SS304L wall, the amount of transformed martensite increased as the distance between the tested specimen and substrate increased, resulting in an increase in ultimate tensile strength with height. The location-dependent martensitic phase transformation and mechanical properties are due to elemental composition heterogeneities during DED component fabrication. Table 2 shows the elemental composition of specimens from top and bottom of the $90 \%$ SS304L wall, in which the wt.\% of $\mathrm{Si}, \mathrm{Mn}, \mathrm{Cr}$, and $\mathrm{Ni}$ decreased as the sample height increased. In AM, the temperature of the molten pool increases with the distance from the substrate as heat accumulates with the addition of new layers $[25,26,47,48]$. Since volatile elements vaporize with increased temperature, these elements are depleted with increasing height. In SS304, the most volatile elements are $\mathrm{Mn}, \mathrm{Cr}$, and $\mathrm{Ni}$ [27]; thus, these elements were found to be depleted at the top compared to the bottom of the $90 \%$ SS304L wall, as shown in Table 2. As Mn, Cr, and Ni are austenite stabilizers, the decrease in wt.\% of these elements reduces austenite stability and results 
in an increase in the volume fraction of transformed martensite and ultimate tensile strength with height.

In the $80 \%$ SS304L wall, the elemental composition also varied with height. There was a slight increase in wt.\% of $\mathrm{Si}, \mathrm{Mn}, \mathrm{Cr}$, and $\mathrm{Ni}$ from the bottom to the top of the wall, leading to a small decrease in transformed martensite content and ultimate tensile strength as the height increases (Figures $5 \mathrm{c}$ and $5 \mathrm{~b}$ ). This trend, which is opposite of that seen in the 90\% SS304L wall, is possibly due to insufficient melting of Fe and SS304L powder during deposition. The trend of chemistry with height due to insufficient melting is beyond the scope of the present study, which aims to connect the chemistry to phase transformation kinetics and mechanical properties.

\subsection{Martensitic phase transformation kinetics under uniaxial tension}

In Figure 8, the ferrite number and true stress are plotted as a function of true strain for representative samples from all three walls and the annealed SS304L for loading/unloading uniaxial tension tests used in in situ measurement of martensite evolution. Due to Villari effect, the feritescope output increases during elastic unloading and decreases during elastic loading, as shown in Figure $8[33,38]$. The feritescope signal measured from the unloaded samples is taken to be the actual FN, as the Villari effect is minimized in the stress-free samples. The FN increased with plastic strain in the specimens from the $80 \%$ and $90 \%$ SS304L walls and the annealed SS304L substrate (Figures 8b-d), but remained almost constant in the specimens extracted from the 100\% SS304L wall (Figure 8a). A significant amount of austenite transformed to martensite in the specimens from the $80 \%$ and $90 \%$ SS304L walls and the 
annealed SS304L substrate, while little to no martensite developed in samples extracted from the 100\% SS304L wall, which agrees with results shown in Table 3.

The feritescope output, FN, can be converted to martensite volume fraction using Eqn. (1). The conversion factor, $k$, in Eqn. (1) was determined from neutron diffraction measurements on annealed SS304L. Figure 9 shows neutron diffraction patterns in an undeformed grip and a plastically deformed region of SS304L, in which the intensity of the (111), (200), (220), (311), and (222) fcc peaks (austenite) decreased and the intensity of the (211) and (111) bcc peaks (which include ferrite and martensite) increased with plastic deformation. The feritescope readings for all undeformed annealed SS304L specimens were below $3 \mathrm{FN}$, indicating the ferrite and any pre-exist martensite were below 5 vol.\% in this material using the conversion factor described below. Therefore, the newly formed peaks from bcc phase in Figure 9 are due to strain-induced martensitic phase transformation. Here, we used the (311) peak from austenite and the (211) peak from martensite, which were better defined and less affected by texture compared to other peaks, to compute volume fractions of the two phases as a function of strain using Eqns. (2) - (4) and the parameters in Table 6. The average calculated martensite volume fraction, $c$, from patterns in the length and thickness directions were plotted as a function of the corrected feritescope reading, $S_{F e, c}$, as shown in Figure 10, to find the conversion factor. Here, the unit of the feritescope reading is presented as vol.\% ferrite, which represents the volume fraction of the ferromagnetic phases and can be converted to/from FN using a calibration curve [55]. From Figure 10, the conversion factor was found to be 1.8, which is in line with the literature on annealed and rolled austenitic stainless steels [31,33].

The strain-induced martensite content increases with plastic strain. In an early study of strain-induced martensitic transformation performed by Cottrell [63], phase transformation was 
observed in carbon steel in between $250{ }^{\circ} \mathrm{C}$ and $425^{\circ} \mathrm{C}$, and the volume fraction of martensite was found to be linearly proportional to plastic strain. However, in the present materials, the evolution martensite volume fraction with respect to plastic strain was found to have a sigmoidal shape, which is similar to the behavior seen in other austenitic stainless steels reported in the literature $[7,10,11,20,33,64]$. Santacreu et al. [64] proposed a phase transformation kinetics equation to describe the sigmoidal shape of strain-induced martensite content evolution as a function of plastic strain in austenitic stainless steels:

$$
\frac{c}{c_{\max }}=1-\exp \left\{-\left[D\left(\bar{\varepsilon}_{P}\right)\right]^{n}\right\}
$$

where $c_{\max }$ is the saturation value of the strain-induced martensite volume fraction, $n$ and $D$ are material parameters, and $\bar{\varepsilon}_{P}$ is the equivalent plastic strain. As there is no clear anisotropy in yield strength, ultimate tensile strength, or ductility in the walls from Table 3, the properties are assumed be isotropic under uniaxial tension and $\bar{\varepsilon}_{P}$ is taken to be $\bar{\varepsilon}_{V M}$, the isotropic von Mises equivalent plastic strain. If $D$ is assumed to be a variable that depends only on stress state [12], then it is a constant in our study as all specimens from the $80 \%$ and $90 \%$ SS304L walls were loaded under uniaxial tension. The material parameters, $c_{m a x}, n$, and $D$ can be determined by fitting the experimental data on the martensite content as a function of $\bar{\varepsilon}_{V M}$ as shown in Figure 11 for the $80 \%$ and $90 \%$ SS304L walls. Table 7 gives the calibrated values for $c_{\max }, n$, and $D$, and the resulting transformation kinetics plots are shown as lines in Figure 11.

As shown in Figure 11, in the 90\% SS304L wall, the transformation kinetics curve has a higher slope, which represents a higher rate of martensitic phase transformation with respect to plastic strain, in the specimen from the top of the wall than the specimen from the bottom, which agrees with the increase in $\mathrm{M}_{\mathrm{d} 30}$ temperature, or decrease in austenite stability, with height shown in Table 2. In addition, the saturation value of the transformation kinetics curve increases with 
the height. In the $80 \%$ SS304L wall, the transformation kinetics equation curve has a higher slope for the specimen from the bottom of the wall compared to specimens from the top, which agrees with the decrease in $\mathrm{M}_{\mathrm{d} 30}$ temperature, or increase in austenite stability, with height shown in Table 2. The saturation value of the transformation kinetic curve also decreases with the height.

The data were further analyzed to link the chemistry, in terms of the $\mathrm{M}_{\mathrm{d} 30}$ temperature, to the transformation kinetics equation. The parameter $n$ is related to the rate of increase in martensite for a given increment in plastic strain; namely, a small $n$ is indicative of a high rate of phase transformation with plastic strain (Eqn. 12). The parameter $c_{\max }$ describes the saturation value of martensite in the given material, or how much martensite can be formed with an unlimited amount of plastic strain. Figure 12 shows $n$ and $c_{\max }$ versus $\mathrm{M}_{\mathrm{d} 30}$, using data in Tables 2 and 7 from longitudinal samples at different locations in the $80 \%$ and 90\% SS304L walls. There appear to be linear relationships between $n$ and $\mathrm{M}_{\mathrm{d} 30}$ temperature, and $c_{\text {max }}$ and $\mathrm{M}_{\mathrm{d} 30}$ temperature. Therefore, we can describe the parameters for the austenite-to-martensite phase transformation kinetics in additively manufactured stainless steel as a function of chemistry using the below two empirical equations:

$$
\begin{aligned}
& n=-0.12 M_{d 30}+7.2 \\
& c_{\text {max }}=3.2 M_{d 30}-38.8
\end{aligned}
$$

where $\mathrm{M}_{\mathrm{d} 30}$ is given in ${ }^{\circ} \mathrm{C}$.

These relationships show that $n$ decreases and $c_{\max }$ increases with increasing $\mathrm{M}_{\mathrm{d} 30}$ temperature, or decreasing austenite stability. The decrease in $n$ with increasing $\mathrm{M}_{\mathrm{d} 30}$ is indicative of a higher rate of phase transformation with decreasing austenite stability, meaning for the same plastic strain, more austenite will transform to martensite for a material with a lower 
austenite stability. The increase in $c_{\max }$ with increase in $\mathrm{M}_{\mathrm{d} 30}$ indicates that the lower the austenite stability, the higher the potential for phase transformation. Both of these trends are physically consistent with the fact that more austenite transforms to martensite when the austenite is metastable versus stable.

\section{Summary and conclusions}

The 304L stainless steel walls with different initial powder chemistry were built by DED to study the effect of chemistry, namely powder chemistry and local elemental variations due to vaporization during processing, on the heterogeneous strain-induced martensitic phase transformation kinetics and tensile mechanical properties. The primary findings of this work are as follows:

- By mixing pre-alloyed SS304L powder (atomized in nitrogen) with Fe powder, the weight fraction of austenite stabilizers was successfully decreased, which activated strain-induced austenite-to-martensite phase transformation. The occurrence of phase transformation in specimens from $80 \%$ and $90 \%$ SS304L walls improved their ultimate tensile strengths and elongations to failure over those in the $100 \%$ SS304L wall. The microstructural phase transformation results in an increased strain-hardening rate and stabilization of the neck, resulting in increased ductility over samples with no phase transformation.

- The chemical composition in components made by AM depends on thermal history, and therefore, location. During AM, as the distance from the substrate increases, and heat builds up in the build as layers are added, the temperature of the molten pool increases; 
thus, the concentration of volatile elements in the molten pool decreases as those elements are preferentially vaporized. In SS304L, the concentrations of austenite stabilizers Cr, Mn, and Ni decreased with height in the 90\% SS304L wall. This resulted in a decrease in austenite stability and an increase in martensitic phase transformation with height, which resulted in an increase in ultimate tensile strength with height.

- The martensitic phase transformation kinetics depend strongly on chemical composition. As the wt.\% of austenite stabilizers decreased, the stability of austenite decreased and the rate of martensite formation with respect to plastic strain increased. The saturation value of the strain-induced martensite volume fraction also increased as the wt.\% of austenite stabilizers decreased. We present a chemistry-dependent phase transformation kinetics equation that describe the rate, with respect to plastic strain, and saturation value of phase transformation in austenitic stainless steels fabricated via AM.

- In additive manufacturing, it is necessary to understand the initial powder chemistry as well as spatial chemical composition variations due to preferential vaporization during deposition. While chemical variation is well-known in welding, it is particularly important to recognize chemical heterogeneity in additive manufacturing as the number of passes in AM is orders of magnitude higher than that encountered in welding; therefore, chemistry may change significantly within a single build, impacting the microstructure and properties of deposited materials. As shown here, in austenitic stainless steels, the elemental composition influences the stability of austenite, which affects the deformation mechanics, namely the strain-induced martensitic phase transformation, which in turn dictates the macroscopic mechanical properties of the material. 


\section{Acknowledgments}

The authors gratefully acknowledge the financial support provided by the National Science Foundation through award number CMMI-1402978. Any opinions, findings, and conclusions or recommendations in the materials are those of the authors and do not necessarily reflect the views of the Nation Science Foundation. We acknowledge Dr. Todd Palmer and Mr. Jay Tressler for component fabrication and Mr. Griffin Jones for the X-ray CT scans at the Center for Innovation Materials Processing through Direct Digital Deposition (CIMP-3D). We acknowledge Dr. Dong Ma and Mr. Matthew Frost of ORNL for neutron diffraction data collection and technical support at the VULCAN beamline. In addition, AMB acknowledges funding from the Oak Ridge Associated Universities Ralph E. Powe Junior Faculty Enhancement Award. 


\section{Figures}
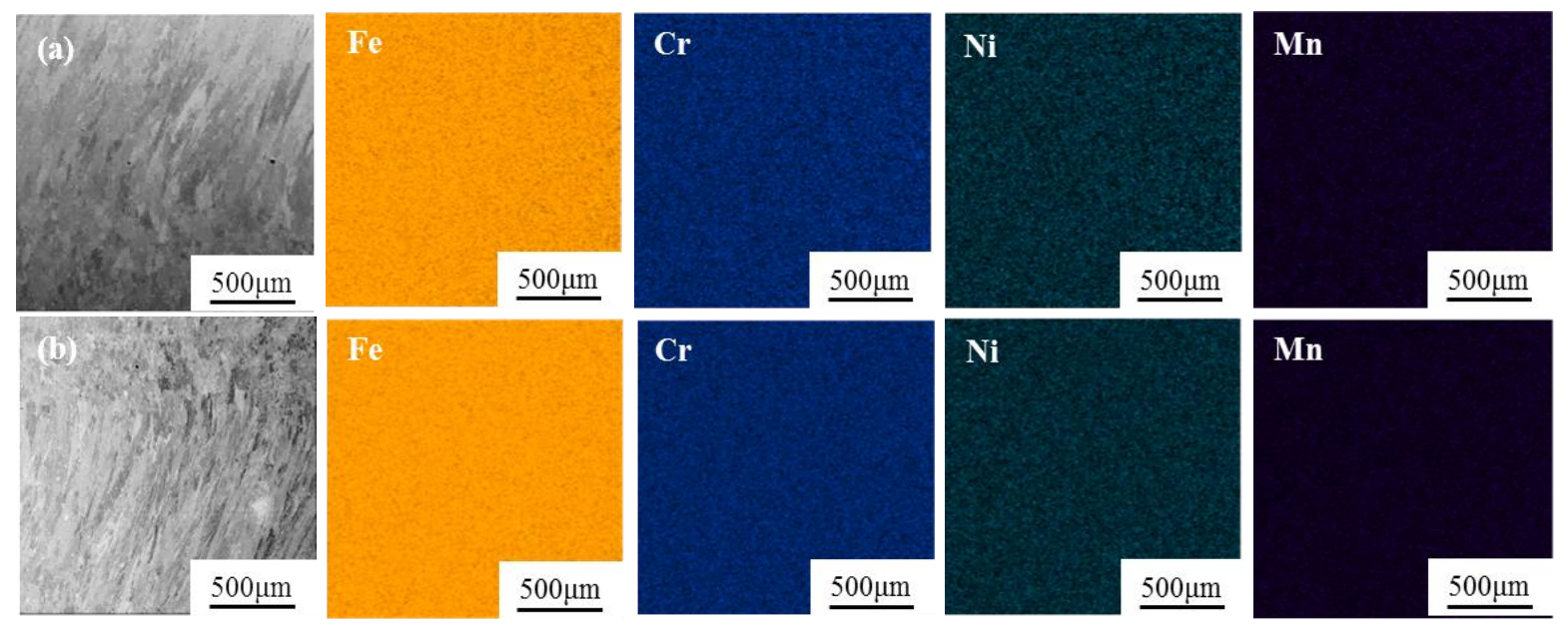

Figure 1. EDS maps of a representative region from the (a) bottom grip and (b) top grip of a transverse specimen from the $90 \%$ SS304L wall showing uniform distribution of major elements. 


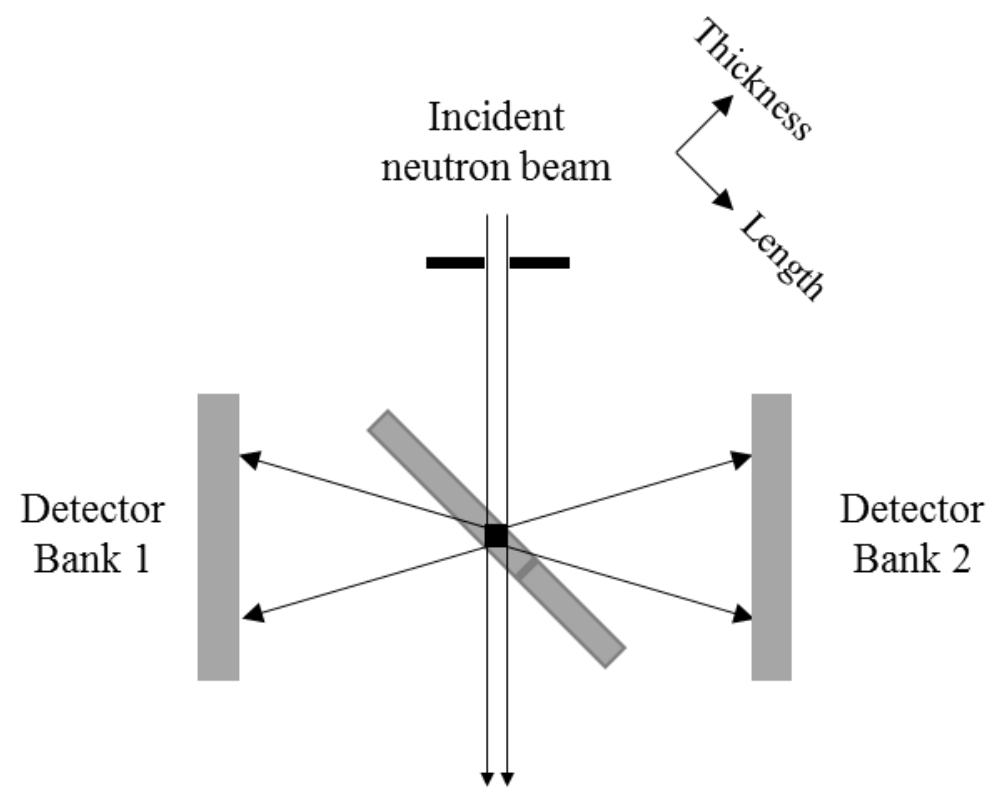

Figure 2. Schematic of neutron diffraction experimental setup, in which diffraction signals from length and thickness directions were collected. 


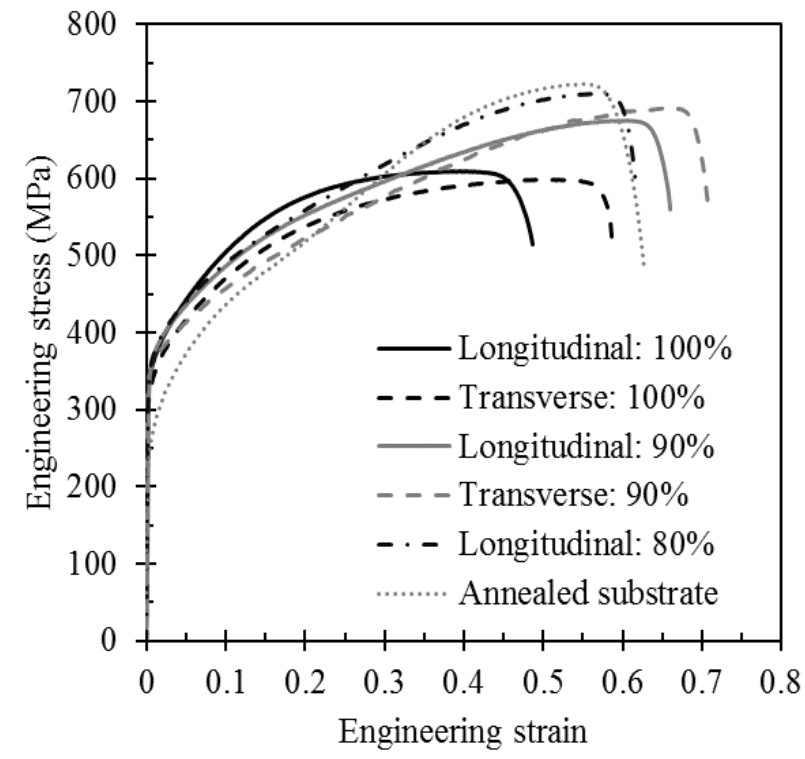

Figure 3. Representative engineering stress-strain curves of uniaxial tension samples extracted from $100 \%$, 90\%, and $80 \%$ SS304L walls in two directions, compared with the annealed SS304L substrate. 


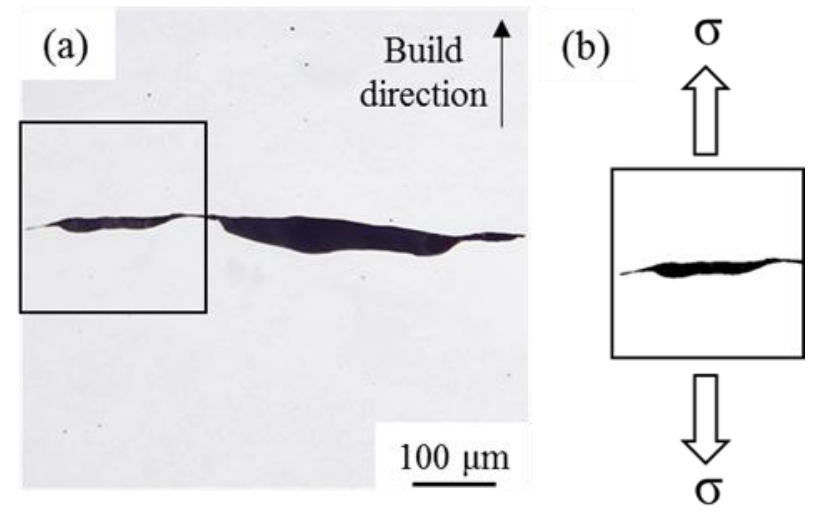

Figure 4. (a) Optical micrograph showing a lack-of-fusion pore in the 80\% SS304L wall. (b) Inset in (a) showing that tension applied in the transverse direction (denoted by the vertical arrows) will open the lack-of-fusion pore. 

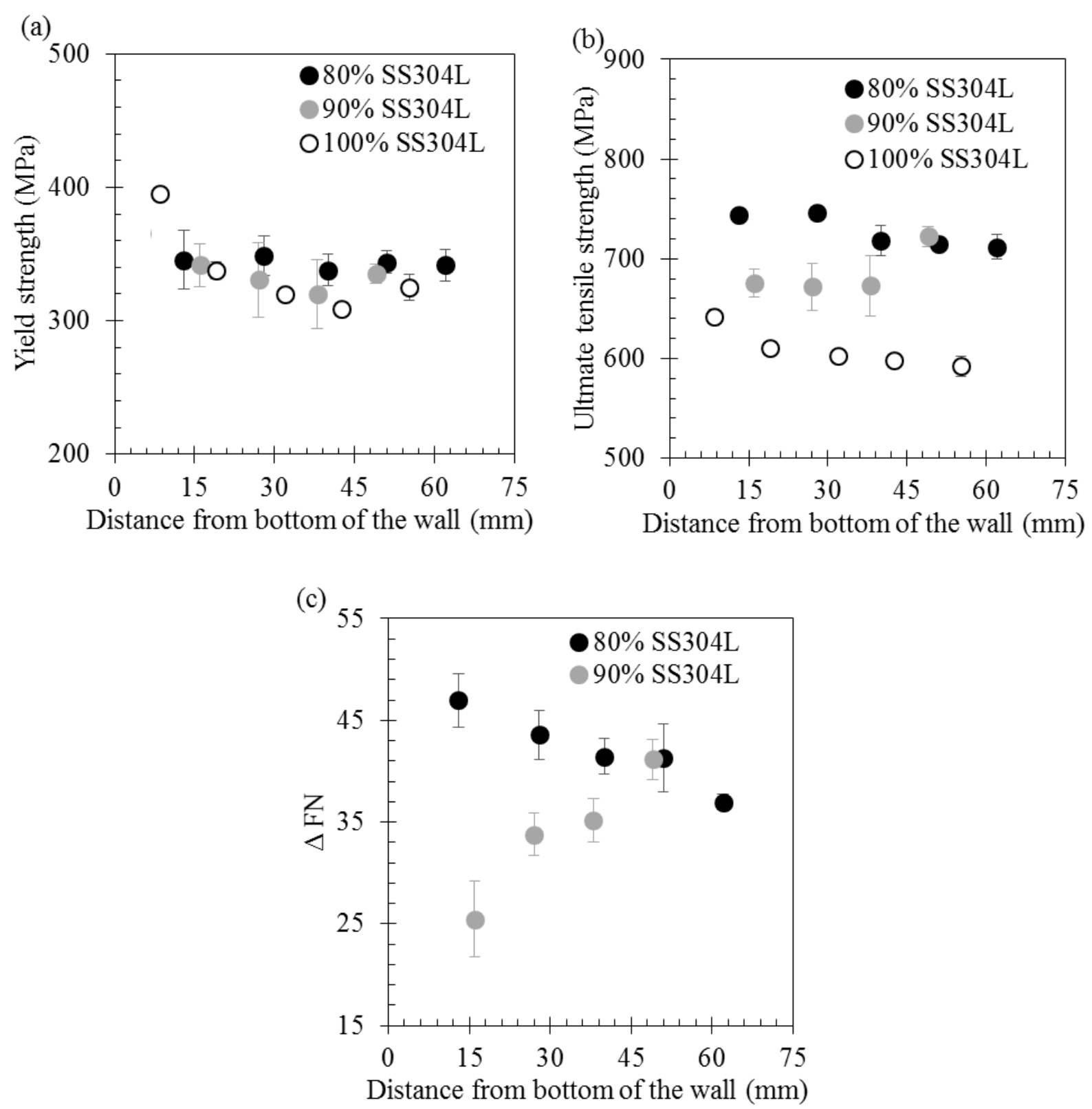

Figure 5. (a) Yield strength, (b) ultimate tensile strength, and (c) $\Delta \mathrm{FN}$ as a function of distance of the sample gauge region from the substrate in the $80 \%, 90 \%$, and $100 \%$ SS304L walls. 


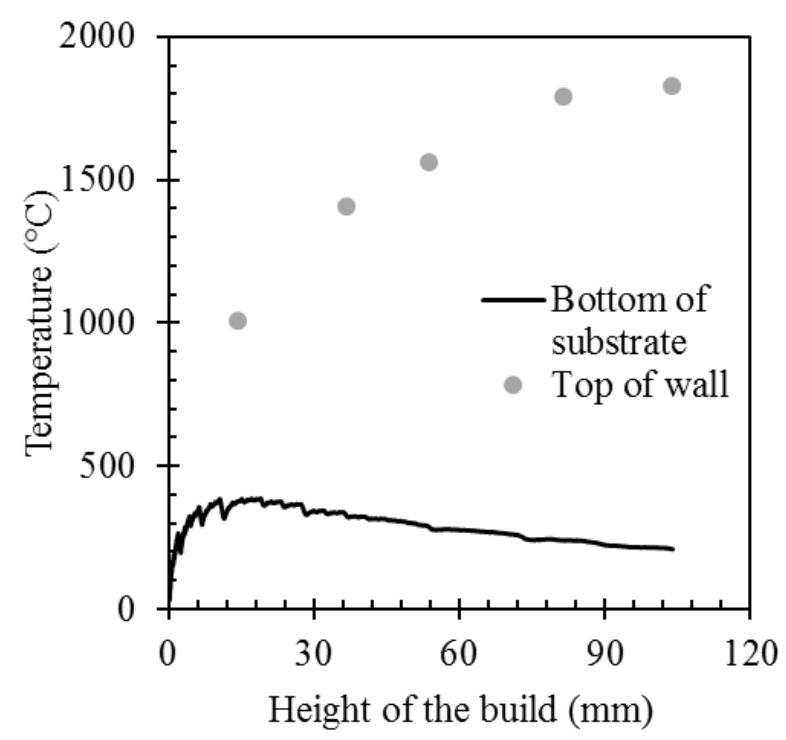

Figure 6. Measured temperature at the bottom of the substrate, and computationally predicted temperature of the top layer of the build, as a function of the height of the build. 

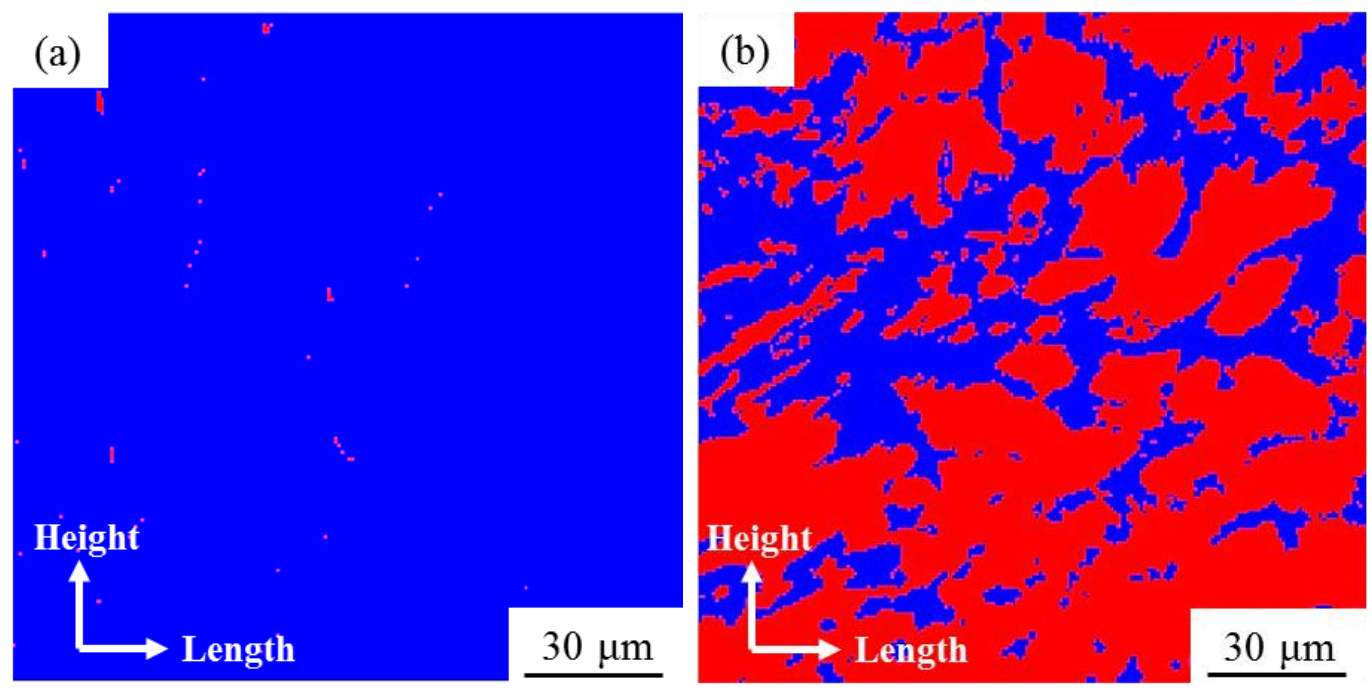

Iron bec

Iron fcc

Figure 7. EBSD phase maps from a longitudinal specimen extracted from the $90 \%$ SS304L wall (a) before plastic deformation, and (b) after plastic deformation under uniaxial tension to a total engineering strain of $66 \%$. 
(a)

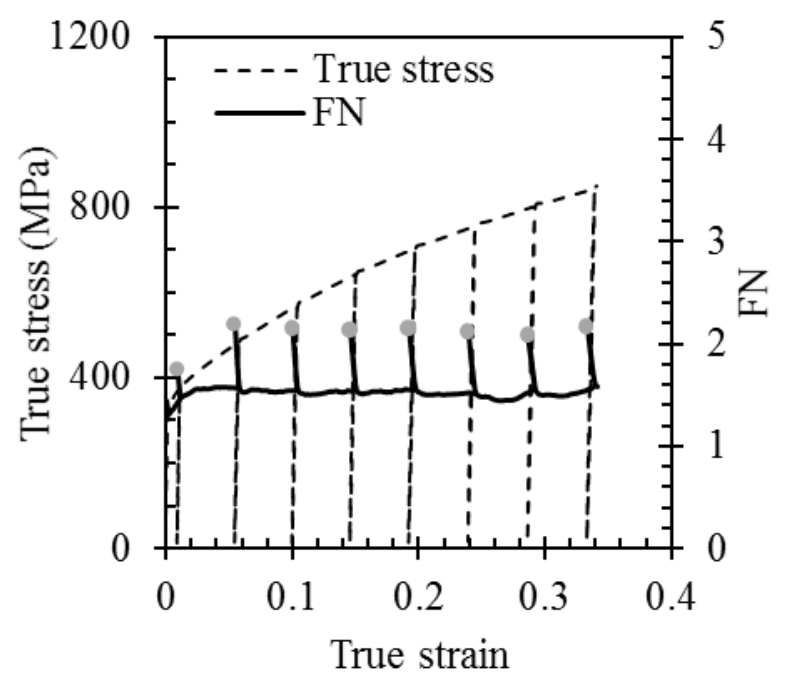

(c)

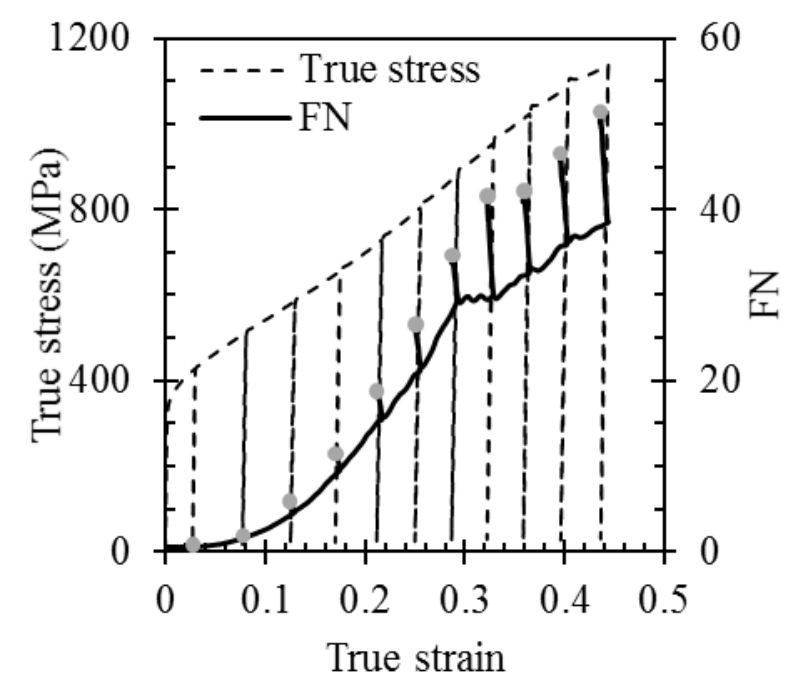

(b)

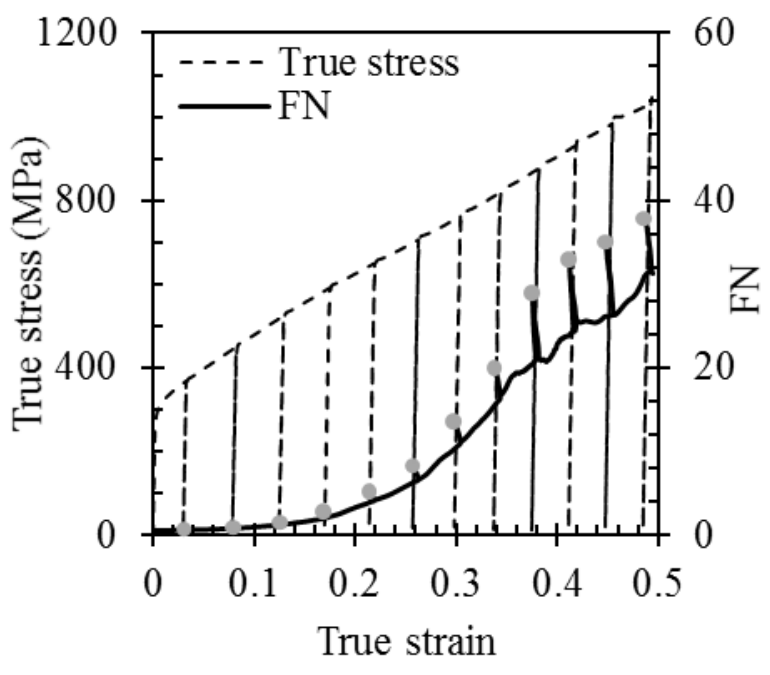

(d)

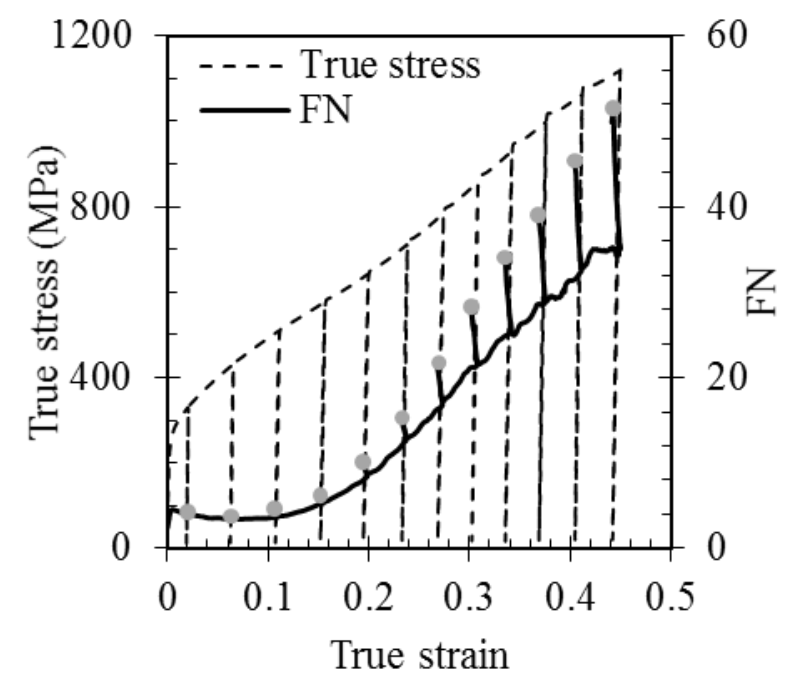

Figure 8. True stress and FN as a function of true strain in representative samples from (a) the top of the $100 \%$ SS304L wall, (b) the top of the $90 \%$ SS304L wall, (c) the top of the $80 \%$ SS304L wall, and (d) the annealed SS304L substrate. Gray symbols represent actual FN measured in stress-free conditions. 

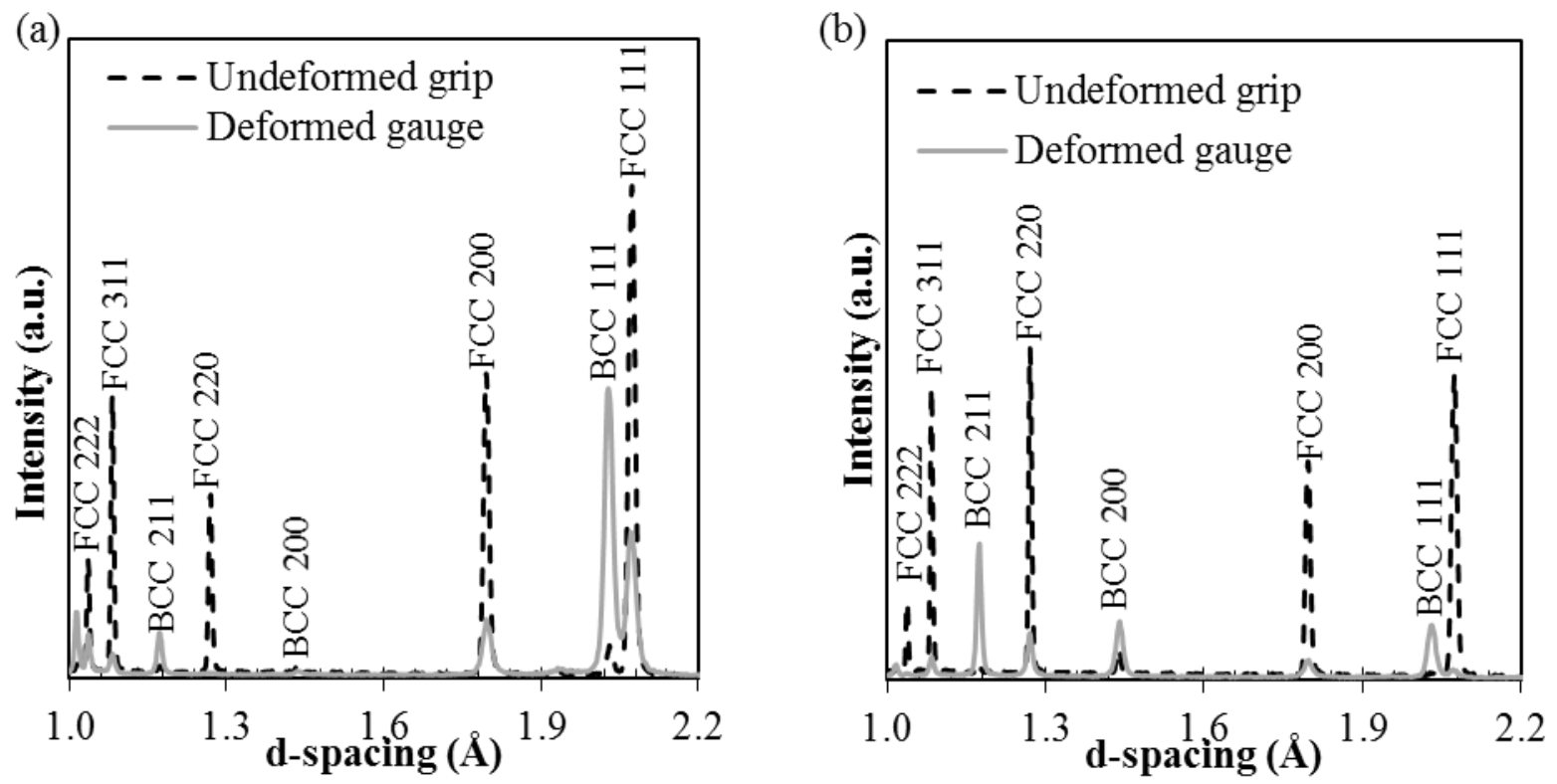

Figure 9. Neutron diffraction patterns for a specimen from the annealed SS304L substrate in the (a) length direction (Bank 1), and (b) thickness direction (Bank 2), showing the contrast between signals in undeformed and deformed (66\% engineering strain under uniaxial tension) regions. 


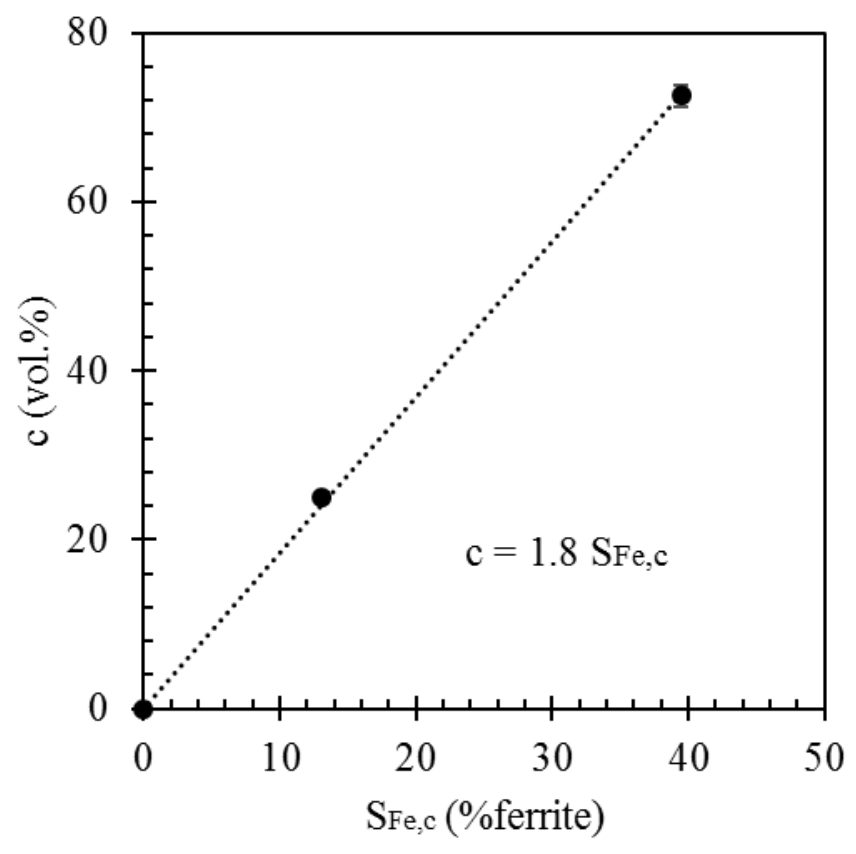

Figure 10. Martensite content, $c$, measured by neutron diffraction as a function of the corrected feritescope reading, $S_{F e, c}$, showing a conversion factor, $k$, from volume fraction of ferrite to volume fraction of martensite of 1.8. 


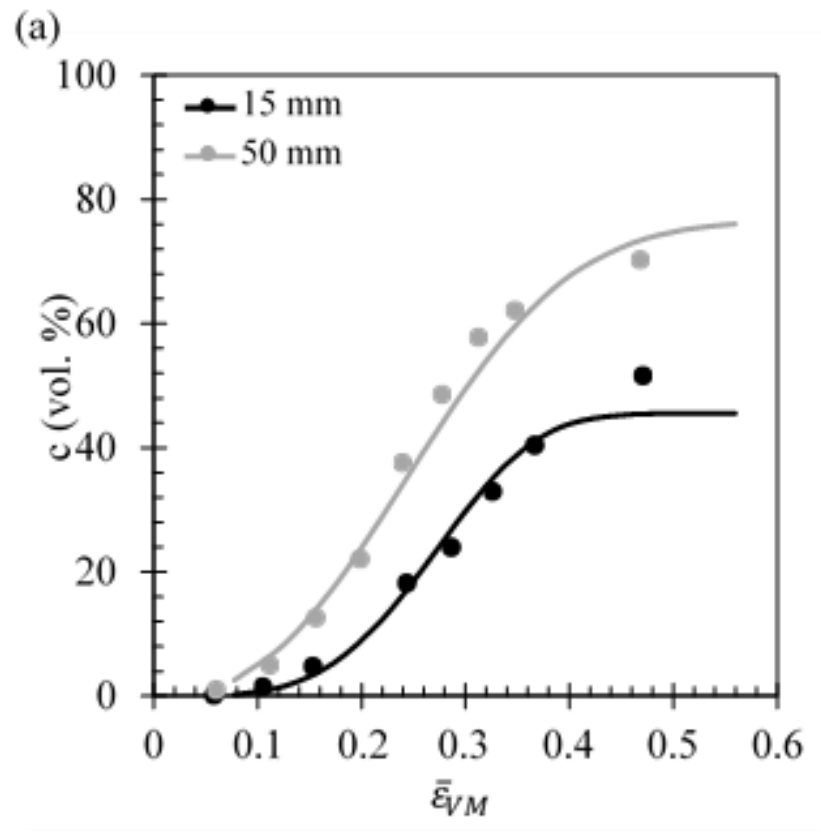

(b)

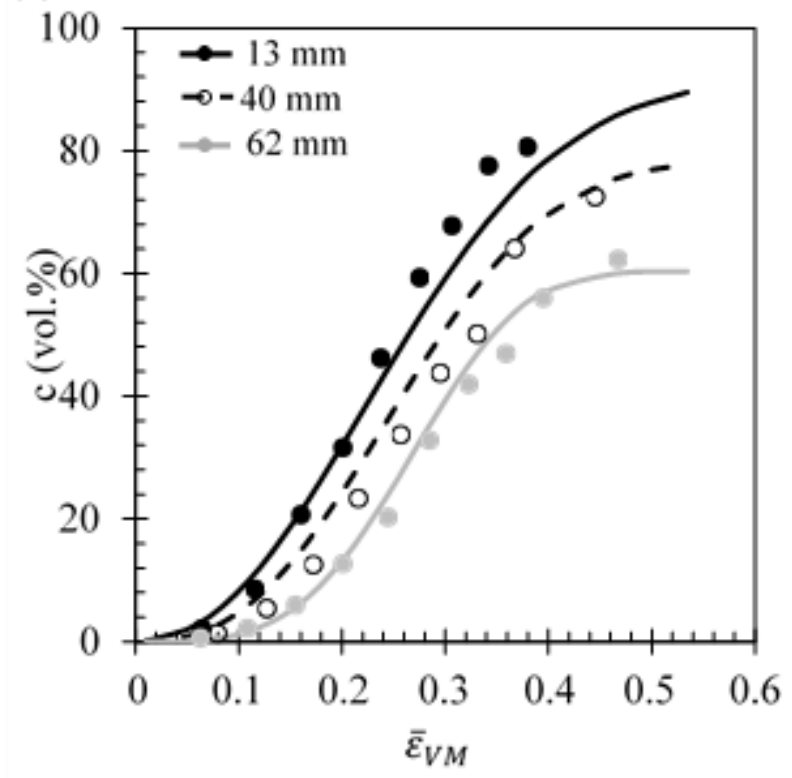

Figure 11. Martensite volume fraction, $c$, as a function of von Mises equivalent plastic strain, $\bar{\varepsilon}_{V M}$, in longitudinal samples at different locations from the (a) $80 \%$, and (b) 90\% SS304L walls. Symbols correspond to experimental data and lines correspond to calibrated transformation kinetics equations. 

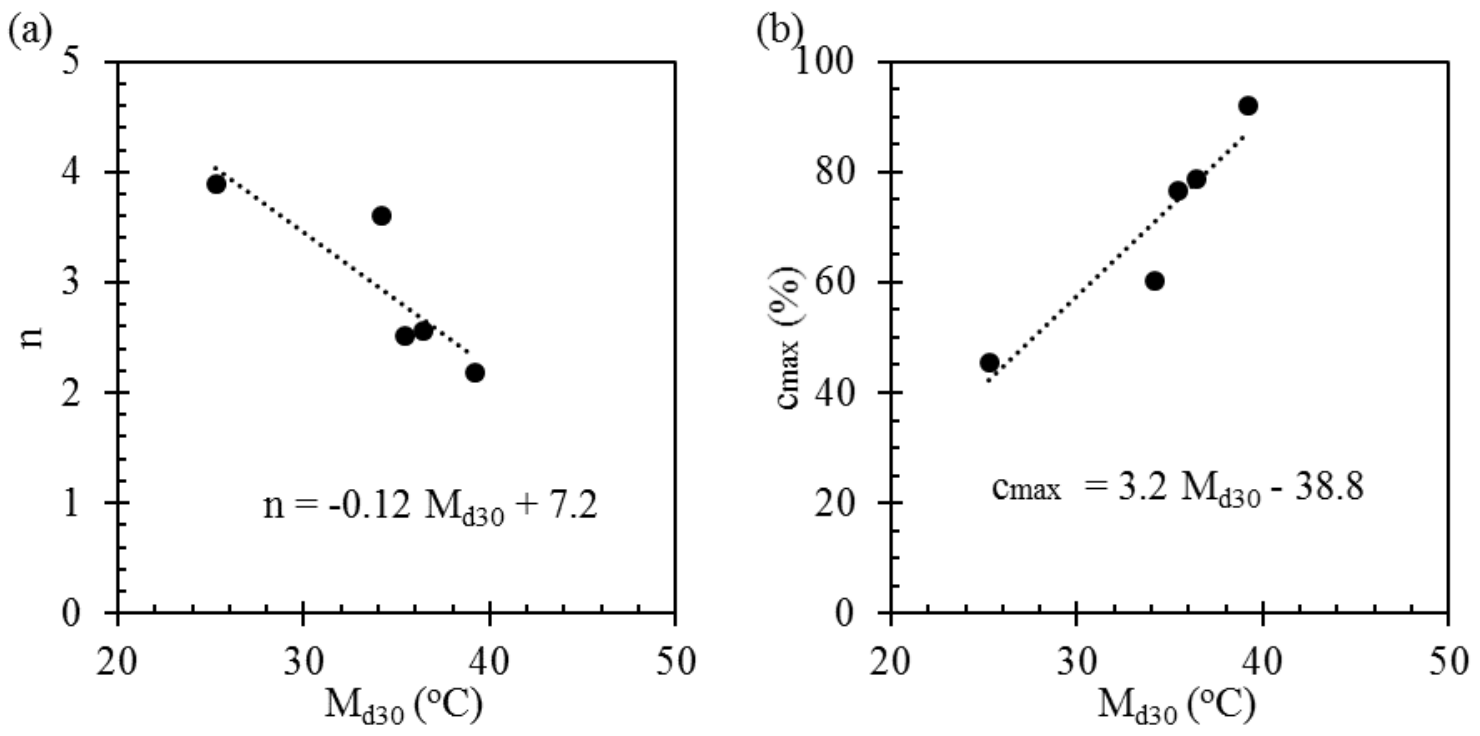

Figure 12. Transformation kinetics parameters (a) $n$, and (b) $c_{\max }$ as a function of $\mathrm{M}_{\mathrm{d} 30}$ temperature in longitudinal samples from different locations in the $80 \%$ and 90\% SS304L walls. The fitted lines were used to quantitatively link $n$ and $c_{\max }$ to the $\mathrm{M}_{\mathrm{d} 30}$ temperature. 
Tables

Table 1. AM processing parameters used to fabricate $80 \%, 90 \%$, and $100 \%$ SS304L walls.

\begin{tabular}{|c|c|c|c|}
\hline & $\mathbf{8 0 \%}$ SS304L wall & $\mathbf{9 0 \%}$ SS304L wall & 100\% SS304L wall \\
\hline $\begin{array}{c}\text { Powder } \\
\text { composition }\end{array}$ & $\begin{array}{c}\text { 80 vol.\% SS304L } \\
\text { powder + 20 vol.\% Fe } \\
\text { powder }\end{array}$ & $\begin{array}{c}\text { 90 vol.\% SS304L } \\
\text { powder + 10 vol.\% Fe } \\
\text { powder }\end{array}$ & $\begin{array}{c}100 \text { vol.\% SS304L } \\
\text { powder }\end{array}$ \\
\hline Laser power (W) & 2000 & 2000 & 2300 \\
\hline $\begin{array}{c}\text { Scanning speed } \\
\text { (mm/s) }\end{array}$ & 10.6 & 10.6 & 8.5 \\
\hline $\begin{array}{c}\text { Linear heat } \\
\text { input (J/mm) }\end{array}$ & 189 & 189 & 18 \\
\hline $\begin{array}{c}\text { Powder flow } \\
\text { rate (g/min) }\end{array}$ & 15.5 & 15.5 & 2.5 \\
\hline $\begin{array}{c}\text { Hatch spacing } \\
\text { (mm) }\end{array}$ & 2.5 & 2.5 & 1.2 \\
\hline $\begin{array}{c}\text { Layer height } \\
\text { (mm) }\end{array}$ & 1.1 & 1.1 & 187 \\
\hline
\end{tabular}

Table 2. Elemental composition in wt.\% of specimens from the $100 \%, 90 \%$, and $80 \%$ SS304L walls and the annealed SS304L substrate, along with the computed $\mathrm{M}_{\mathrm{d} 30}$ temperatures for each elemental composition.

\begin{tabular}{|c|c|c|c|c|c|c|c|c|c|}
\hline & $\begin{array}{c}\text { Distance } \\
\text { from the } \\
\text { substrate } \\
(\mathbf{m m})\end{array}$ & $\mathbf{C}$ & $\mathbf{N}$ & $\mathbf{S i}$ & $\mathbf{M n}$ & $\mathbf{C r}$ & $\mathbf{N i}$ & $\mathbf{M o}$ & $\begin{array}{c}\mathbf{M}_{\mathbf{d 3 0}} \\
\left({ }^{\mathbf{0}} \mathbf{C}\right)\end{array}$ \\
\hline $\begin{array}{c}\text { SS304L } \\
\text { powder }\end{array}$ & - & 0.01 & 0.08 & 0.5 & 1.5 & 19.0 & 10.3 & 0.01 & -5.3 \\
\hline $\mathbf{1 0 0 \%}$ SS304L & 70 & 0.01 & 0.09 & 0.56 & 1.42 & 18.94 & 9.90 & 0.01 & -3.6 \\
\hline 90\% SS304L & 50 & 0.01 & 0.09 & 0.63 & 1.25 & 16.89 & 8.75 & 0.05 & 35.4 \\
\hline & 15 & 0.01 & 0.09 & 0.7 & 1.31 & 17.05 & 9.47 & 0.05 & 25.3 \\
\hline \multirow{2}{*}{$\mathbf{8 0 \%}$ SS304L } & 40 & 0.01 & 0.09 & 0.64 & 1.27 & 16.73 & 9.08 & 0.05 & 34.2 \\
\cline { 2 - 9 }$y$ & 13 & 0.01 & 0.09 & 0.63 & 1.27 & 16.62 & 8.92 & 0.05 & 36.4 \\
\hline $\begin{array}{c}\text { Annealed } \\
\text { SS304L }\end{array}$ & - & 0.02 & 0.04 & 0.46 & 1.26 & 18.25 & 8.02 & 0.07 & 43.3 \\
\hline \multirow{2}{*}{$\begin{array}{c}\text { Uncertainty } \\
\text { (wt.\%) }\end{array}$} & - & 0.0002 & 0.0003 & 0.0006 & 0.001 & 0.0006 & 0.0006 & 0.0008 & - \\
\hline
\end{tabular}


Table 3. Summary of mechanical properties of samples from 100\%, 90\%, and 80\% SS304L walls compared to the annealed SS304L substrate. Values are given as average \pm standard deviation, and here $n$ indicates the number of tested samples in each condition.

\begin{tabular}{|c|c|c|c|c|c|c|c|}
\hline & \multicolumn{2}{|c|}{$\mathbf{1 0 0 \%}$ SS304L } & \multicolumn{2}{c|}{$\mathbf{9 0 \%}$ SS304L } & \multicolumn{2}{c|}{$\mathbf{8 0 \%}$ SS304L } & $\begin{array}{c}\text { Annealed } \\
\text { SS304L }\end{array}$ \\
\hline & $\begin{array}{c}\text { Longitudinal } \\
\mathbf{n}=\mathbf{1 1}\end{array}$ & $\begin{array}{c}\text { Transverse } \\
\mathbf{n}=\mathbf{7}\end{array}$ & $\begin{array}{c}\text { Longitudinal } \\
\mathbf{n}=\mathbf{1 7}\end{array}$ & $\begin{array}{c}\text { Transverse } \\
\mathbf{n}=\mathbf{2}\end{array}$ & $\begin{array}{c}\text { Longitudinal } \\
\mathbf{n}=\mathbf{1 5}\end{array}$ & $\begin{array}{c}\text { Transverse* } \\
\mathbf{n}=\mathbf{6}\end{array}$ & $\mathbf{n}=\mathbf{4}$ \\
\hline $\begin{array}{c}\text { Yield } \\
\text { strength } \\
\text { (MPa) }\end{array}$ & $337 \pm 29$ & $314 \pm 6$ & $339 \pm 25$ & 342,320 & $342 \pm 12$ & $333 \pm 8$ & $265 \pm 9$ \\
\hline $\begin{array}{c}\text { Ultimate } \\
\text { tensile } \\
\text { strength } \\
\text { (MPa) }\end{array}$ & $609 \pm 18$ & $606 \pm 13$ & $683 \pm 26$ & 700,693 & $722 \pm 16$ & $472 \pm 69$ & $722 \pm 14$ \\
\hline $\begin{array}{c}\text { Elongation } \\
\text { to failure } \\
\text { (\%) }\end{array}$ & $48.2 \pm 2.5$ & $56.4 \pm 5.8$ & $64.3 \pm 3.4$ & $70.7,67.4$ & $60.3 \pm 3.6$ & $14.3 \pm 9.0$ & $63.3 \pm 3.6$ \\
\hline $\begin{array}{c}\Delta \text { Ferrite } \\
\text { number } \\
\text { (FN) }\end{array}$ & $0.9 \pm 0.3$ & $1.3 \pm 0.4$ & $33.3 \pm 5.1$ & $26.6,26.3$ & $41.7 \pm 3.7$ & $3.5 \pm 5.3$ & $41.7 \pm 4.1$ \\
\hline
\end{tabular}

*The transverse samples from the $80 \%$ SS304L wall had lack-of-fusion pores, which reduced all reported properties in transverse specimens.

Table 4. Material properties for steel and aluminum used for finite element simulation, where $\mathrm{T}$ represents temperature in $\mathrm{K}$.

\begin{tabular}{|c|c|c|}
\hline Property & Value & Reference \\
\hline Thermal conductivity of SS316L (W/m/K) & $11.82+0.0106 \mathrm{~T}$ & {$[26]$} \\
\hline Thermal conductivity of $\mathbf{A l}(\mathbf{W} / \mathbf{m} / \mathbf{K})$ & 247 & {$[50]$} \\
\hline $\begin{array}{c}\text { Thermal contact conductance between low carbon steel } \\
\text { and } \mathbf{A l}\left(\mathbf{W} / \mathbf{m}^{\mathbf{2}} / \mathbf{K}\right)\end{array}$ & 1000 & {$[52,65]$} \\
\hline
\end{tabular}

Table 5. Material properties of austenitic stainless steels used for stacking fault energy calculation and calculated Gibbs and stacking fault energies of the 100\%, 90\%, and 80\% SS304L walls.

\begin{tabular}{|c|c|c|c|c|}
\hline & $\mathbf{1 0 0 \%}$ SS304L & 90\% SS304L & $\mathbf{8 0 \%}$ SS304L & Reference \\
\hline $\boldsymbol{\sigma}\left(\mathbf{J} / \mathbf{m}^{2}\right)$ & \multicolumn{3}{|c|}{0.007} & {$[66,67]$} \\
\hline $\boldsymbol{\rho}\left(\mathbf{m o l} / \mathbf{m}^{2}\right)$ & \multicolumn{3}{|c|}{$2.9 \times 10^{-5}$} & {$[61,67]$} \\
\hline$\Delta \mathbf{G}^{\gamma \rightarrow \boldsymbol{\varepsilon}}\left(\mathbf{J} / \mathbf{m o l}^{-5}\right)$ & 331.8 & 216.4 & 205.8 & NA \\
\hline$\gamma_{\mathbf{S F E}}\left(\mathbf{m J} / \mathbf{m}^{2}\right)$ & 33.6 & $26.8-28.8$ & $26.2-27.2$ & NA \\
\hline
\end{tabular}


Table 6. Parameters for martensite content calculation using the internal standard method, where $f$ is the atomic scattering factor of an $\mathrm{Fe}$ atom.

\begin{tabular}{|c|c|c|}
\hline & M & $|\mathbf{F}|^{2}$ \\
\hline (311), fcc & 24 & $16 f^{2}$ \\
\hline (211), bcc & 12 & $4 f^{2}$ \\
\hline
\end{tabular}

Table 7. Calibrated parameters for the martensitic transformation kinetics equation.

\begin{tabular}{|l|c|c|c|c|}
\hline & $\begin{array}{c}\text { Distance from the } \\
\text { bottom of the wall }(\mathbf{m m})\end{array}$ & $\mathbf{c}_{\max }(\mathbf{v o l . \%})$ & $\mathbf{D}$ & $\mathbf{n}$ \\
\hline \multirow{2}{*}{$90 \%$ SS304L } & 15 & 46 & 3.4 & 3.9 \\
\cline { 2 - 5 } & 50 & 77 & 3.4 & 2.5 \\
\hline \multirow{3}{*}{$\mathbf{8 0 \%}$ SS304L } & 13 & 92 & 3.4 & 2.2 \\
\cline { 2 - 5 } & 40 & 79 & 3.4 & 2.6 \\
\cline { 2 - 5 } & 62 & 60 & 3.4 & 3.6 \\
\hline
\end{tabular}




\section{References:}

[1] D.D. Gu, W. Meiners, K. Wissenbach, R. Poprawe, Laser additive manufacturing of metallic components: materials, processes and mechanisms, Int. Mater. Rev. 57 (2012) 133-164. doi:10.1179/1743280411Y.0000000014.

[2] Z. Wang, T.A. Palmer, A.M. Beese, Effect of processing parameters on microstructure and tensile properties of austenitic stainless steel $304 \mathrm{~L}$ made by directed energy deposition additive manufacturing, Acta Mater. 110 (2016) 226-235.

doi:10.1016/j.actamat.2016.03.019.

[3] A. Yadollahi, N. Shamsaei, S.M. Thompson, A. Elwany, L. Bian, Mechanical and Microstructural Properties of Selective Laser Melted 17-4 PH Stainless Steel, Proc. ASME 2015 Int. Mech. Eng. Congr. Expo. (2015) 1-7.

[4] A.M. Beese, B.E. Carroll, Review of Mechanical Properties of Ti-6Al-4V Made by LaserBased Additive Manufacturing Using Powder Feedstock, JOM. 68 (2015) 724-734. doi:10.1007/s11837-015-1759-Z.

[5] Z. Wang, A.D. Stoica, D. Ma, A.M. Beese, Diffraction and single-crystal elastic constants of Inconel 625 at room and elevated temperatures determined by neutron diffraction, Mater. Sci. Eng. A. 674 (2016) 406-412. doi:http://dx.doi.org/10.1016/j.msea.2016.08.010.

[6] D. Ma, A.D. Stoica, Z. Wang, A.M. Beese, Crystallographic texture in an additively manufactured nickel-base superalloy, Mater. Sci. Eng. A. 684 (2017) 47-53.

[7] F. Lecroise, A. Pineau, Martensitic Transformations Induced By Plastic-Deformation in Fe-Ni-Cr-C System, Metall. Trans. 3 (1972) 387-396. <Go to ISI>://A1972L595400003.

[8] T. Angel, Formation of Martensite in Austenitic Stainless Steels, effect of deformation, temperature and composition, J. Iron Steel Inst. (1954) 165-174.

[9] G.B. Olson, M. Cohen, A mechanism for the strain-induced nucleation of martensitic transformations, J. Less- Common Met. 28 (1972) 107-118.

[10] R.G. Stringfellow, D.M. Parks, G.B. Olson, A constitutive model for transformation plasticity accompanying strain-induced martensitic transformations in metastable austenitic steels, Acta Metall. Mater. 40 (1992) 1703-1716. doi:10.1016/09567151(92)90114-T.

[11] G.B. Olson, M. Cohen, Kinetics of strain-induced martensitic nucleation, Metall. Trans. A. 6 (1975) 791-795. doi:10.1007/BF02672301.

[12] A.M. Beese, D. Mohr, Effect of stress triaxiality and Lode angle on the kinetics of straininduced austenite-to-martensite transformation, Acta Mater. 59 (2011) 2589-2600. http://linkinghub.elsevier.com/retrieve/pii/S1359645410008724 (accessed August 29, 2014).

[13] J.B. Leblond, Mathematical modelling of transformation plasticity in steels II: Coupling with strain hardening phenomena, Int. J. Plast. 5 (1989) 573-591. doi:10.1016/07496419(89)90002-8.

[14] R.G. Stringfellow, D.M. Parks, A self-consistent model of isotropic viscoplastic behavior in multiphase materials, Int. J. Plast. 7 (1991) 529-547.

[15] A.M. Beese, D. Mohr, Anisotropic plasticity model coupled with Lode angle dependent strain-induced transformation kinetics law, J. Mech. Phys. Solids. 60 (2012) 1922-1940. doi:10.1016/j.jmps.2012.06.009.

[16] G.W. Greenwood, R.H. John, The deformation of metals under small stresses during phase transformations, Proc. R. Soc. Lond. A. Math. Phys. Sci. 283 (1965) 403-422. 
[17] J.R. Patel, M. Cohen, Criterion for the action of applied stress in the martensitic transformation, Acta Metall. 1 (1953) 531-538. doi:10.1016/0001-6160(53)90083-2.

[18] J. Talonen, Effect of strain-induced $\alpha$ '-martensite transformation on mechanical properties of metastable austenitic stainless steels, Helsinki University of Technology, 2007.

[19] L. Facchini, N. Vicente, I. Lonardelli, E. Magalini, P. Robotti, M. Alberto, Metastable austenite in 17-4 precipitation-hardening stainless steel produced by selective laser melting, Adv. Eng. Mater. 12 (2010) 184-188. doi:10.1002/adem.200900259.

[20] J. Talonen, H. Hänninen, Formation of shear bands and strain-induced martensite during plastic deformation of metastable austenitic stainless steels, Acta Mater. 55 (2007) 61086118. doi:10.1016/j.actamat.2007.07.015.

[21] K. Tomimura, S. Takaki, S. Tanimoto, Y. Tokunaga, Optimal Refining Chemical Composition in Fe-Cr-Ni Alloys for Ultra Grain by Reversion from Deformation Induced Martensite, ISIJ Int. 31 (1991) 721-727.

[22] B.E. Carroll, T.A. Palmer, A.M. Beese, Anisotropic tensile behavior of Ti-6Al-4V components fabricated with directed energy deposition additive manufacturing, Acta Mater. 87 (2015) 309-320. doi:10.1016/j.actamat.2014.12.054.

[23] T. Mukherjee, J.S. Zuback, A. De, T. DebRoy, Printability of alloys for additive manufacturing, Sci. Rep. 6 (2016) 1-8. doi:10.1038/srep19717.

[24] H.K. Rafi, D. Pal, N. Patil, T.L. Starr, B.E. Stucker, Microstructure and Mechanical Behavior of 17-4 Precipitation Hardenable Steel Processed by Selective Laser Melting, J. Mater. Eng. Perform. 23 (2014) 4421-4428. doi:10.1007/s11665-014-1226-y.

[25] Z. Wang, E. Denlinger, P. Michaleris, A.D. Stoica, D. Ma, A.M. Beese, Residual stress mapping in Inconel 625 fabricated through additive manufacturing: Method for neutron diffraction measurements to validate thermomechanical model predictions, Mater. Des. 113 (2017) 169-177. doi:10.1016/j.matdes.2016.10.003.

[26] V. Manvatkar, A. De, T. DebRoy, Spatial variation of melt pool geometry, peak temperature and solidification parameters during laser assisted additive manufacturing process, Mater. Sci. Technol. 31 (2015) 924-930. doi:10.1179/1743284714Y.0000000701.

[27] X. He, T. DebRoy, P.W. Fuerschbach, Composition change of stainless steel during microjoining with short laser pulse, J. Appl. Phys. 96 (2004) 4547-4555. doi:10.1063/1.1785868.

[28] ASTM A479/A479M: Standard Specification for Stainless Steel Bars and Shapes for Use in Boilers and Other Pressure Vessels, West Conshohocken, PA, 2015. doi:10.1520/A0479.

[29] ASTM Standard E8/E8M-15a: Standard Test Methods for Tension Test of Metallic Materials, West Conshohocken, PA, 2015.

[30] G. Ziółkowski, E. Chlebus, P. Szymczyk, J. Kurzac, Application of X-ray CT method for discontinuity and porosity detection in $316 \mathrm{~L}$ stainless steel parts produced with SLM technology, Arch. Civ. Mech. Eng. (2014) 1-7. doi:10.1016/j.acme.2014.02.003.

[31] J. Talonen, P. Aspegren, H. Hänninen, Comparison of different methods for measuring strain induced $\alpha$-martensite content in austenitic steels, Mater. Sci. Technol. 20 (2004) 1506-1512. doi:10.1179/026708304X4367.

[32] W. Staib, D.I.H. Kunzel, In-situ Ferrite Content Measurement of Duplex Steel Structures in the Chemical Industry. Practical Applications of the Alternating Field, Magnetoinductive Method, Nondestruct. Charact. Mater. (1989) 614-621. 
[33] A.M. Beese, D. Mohr, Identification of the Direction-Dependency of the Martensitic Transformation in Stainless Steel Using In Situ Magnetic Permeability Measurements, Exp. Mech. 51 (2011) 667-676. doi:10.1007/s11340-010-9374-y.

[34] M. Shimotomai, K. Maruta, K. Mine, M. Matsui, Formation of aligned two-phase microstructures by applying a magnetic field during the austenite to ferrite transformation in steels, Acta Mater. 51 (2003) 2921-2932. doi:10.1016/S1359-6454(03)00106-X.

[35] T. LeBrun, T. Nakamoto, K. Horikawa, H. Kobayashi, Effect of Retained Austenite on Subsequent Thermal Processing and Resultant Mechanical Properties of Selective Laser Melted 17-4 PH Stainless Steel, Mater. Des. 81 (2015) 44-53. doi:10.1016/j.matdes.2015.05.026.

[36] S.S.M. Tavares, D. Gunderov, V. Stolyarov, J.M. Neto, Phase transformation induced by severe plastic deformation in the AISI 304L stainless steel, Mater. Sci. Eng. A. 358 (2003) 32-36. doi:10.1016/S0921-5093(03)00263-6.

[37] R.D.K. Misra, B.R. Kumar, M. Somani, P. Karjalainen, Deformation processes during tensile straining of ultrafine/nanograined structures formed by reversion in metastable austenitic steels, Scr. Mater. 59 (2008) 79-82. doi:10.1016/j.scriptamat.2008.02.028.

[38] A. Bienkowski, The magneto-elastic villari effect in ferrites, J. Magn. Magn. Mater. 19 (1980) 120-122.

[39] P. Reu, Virtual Strain Gage Size Study, Exp. Tech. 39 (2015) 1-3.

[40] K. An, H.D. Skorpenske, A.D. Stoica, D. Ma, X.L. Wang, E. Cakmak, First in situ lattice strains measurements under load at VULCAN, Metall. Mater. Trans. A Phys. Metall. Mater. Sci. 42 (2011) 95-99. doi:10.1007/s11661-010-0495-9.

[41] T. Ungar, A.D. Stoica, G. Tichy, X.-L. Wang, Orientation-dependent evolution of the dislocation density in grain populations with different crystallographic orientations relative to the tensile axis in a polycrystalline aggregate of stainless steel, Acta Mater. 66 (2014) 251-261. doi:10.1016/j.actamat.2013.11.012.

[42] G.M. Stoica, A.D. Stoica, M.K. Miller, D. Ma, Temperature-dependent elastic anisotropy and mesoscale deformation in a nanostructured ferritic alloy., Nat. Commun. 5 (2014) 18. doi:10.1038/ncomms6178.

[43] K. An, VDRIVE-Data Reduction and Interactive Visulaization Softwarew for Event Mode Neutron Diffraction, ORNL Report, Oak Ridge National Laboratory, 2012.

[44] R.L. Snyder, The Use of Reference Intensity Ratios in X-Ray Quantitative Analysis, Powder Diffr. 7 (1992) 186-193. doi:10.1017/S0885715600018686.

[45] ASTM E1019: Standard Test Methods for Determination of Carbon, Sulfur, Nitrogen , and Oxygen in Steel and in Iron , Nickel, and Cobalt Alloys by Various Combusition and Fusion Techniques, in: ASTM Int., West Conshohocken, PA, 2015: pp. 1-28.

doi:10.1520/E1019-11.Copyright.

[46] ASTM E1086: Standard Test Method for Analysis of austenitic Stainless Steel by Spark Atomic Emission Spectrometry, West Conshohocken, PA, 2015. doi:10.1520/E1086-14.2.

[47] X. Wu, A review of laser fabrication of metallic engineering components and of materials, Mater. Sci. Technol. 23 (2007) 631-640. doi:10.1179/174328407X179593.

[48] K. Zhang, S. Wang, W. Liu, X. Shang, Characterization of stainless steel parts by Laser Metal Deposition Shaping, Mater. Des. 55 (2014) 104-119. doi:10.1016/j.matdes.2013.09.006.

[49] Abaqus, Reference Manuals v6.14, Abaqus Inc. (2014).

[50] D. Chung, Materials for thermal conduction, Appl. Therm. Eng. 21 (2001) 1593-1605. 
doi:10.1016/S1359-4311(01)00042-4.

[51] Man-systems Integration Standards, Natl. Aeronaut. Sp. Adm. (1995). https://msis.jsc.nasa.gov/sections/section04.htm (accessed January 1, 2017).

[52] H. Yüncü, Thermal contact conductance of nominaly flat surfaces, Heat Mass Transf. 43 (2006) 1-5. doi:10.1007/s00231-006-0087-9.

[53] ISO 8249:2000 (en): Welding — Determination of Ferrite Number (FN) in austenitic and duplex ferritic-austenitic Cr-Ni stainless steel weld metals, 2000.

[54] P.K. Palani, N. Murugan, Prediction of Delta Ferrite Content and Effect of Welding Process Parameters in Claddings by FCAW, Mater. Manuf. Process. 21 (2006) 431-438. doi:10.1080/10426910500471409.

[55] Fischer, Operator's Manual for Feritescope FMP30 Manual, 2008.

[56] P.L. Mangonon, G. Thomas, Structure and properties of thermal-mechanically treated 304 stainless steel, Metall. Trans. 1 (1970) 1587-1594. doi:10.1007/BF02642004.

[57] K. Spencer, J.D. Embury, K.T. Conlon, M. Véron, Y. Bréchet, Strengthening via the formation of strain-induced martensite in stainless steels, Mater. Sci. Eng. A. 387-389 (2004) 873-881. doi:10.1016/j.msea.2003.11.084.

[58] M. Moallemi, A. Kermanpur, A. Najafizadeh, A. Rezaee, H.S. Baghbadorani, P.D. Nezhadfar, Deformation-induced martensitic transformation in a 201 austenitic steel: The synergy of stacking fault energy and chemical driving force, Mater. Sci. Eng. A. 653 (2016) 147-152. doi:10.1016/j.msea.2015.12.006.

[59] S. Curtze, V.T. Kuokkala, Dependence of tensile deformation behavior of TWIP steels on stacking fault energy, temperature and strain rate, Acta Mater. 58 (2010) 5129-5141. doi:10.1016/j.actamat.2010.05.049.

[60] G.B. Olson, M. Cohen, A General Mechanism of Martensitic Nucleation: Part I. General Concepts and the FCC - HCP Transformation, Metall. Trans. A. 7A (1976) 1897-1904. doi:10.1007/BF02659822.

[61] S. Curtze, V.T. Kuokkala, A. Oikari, J. Talonen, H. Hänninen, Thermodynamic modeling of the stacking fault energy of austenitic steels, Acta Mater. 59 (2011) 1068-1076. doi:10.1016/j.actamat.2010.10.037.

[62] I.A. Yakubtsov, A. Ariapour, D.D. Perovic, Effect of nitrogen on stacking fault energy of f.c.c. iron-based alloys, Acta Mater. 47 (1999) 1271-1279. doi:10.1016/S13596454(98)00419-4.

[63] A.H. Cottrell, Tensile Properties of Unstable Austenite and Its Low-Teperature Decomposition Products, J. Iron Steel Inst. 151 (1945) 93-104.

[64] P.O. Santacreu, J.C. Glez, G. Chinouilh, T. Frohlich, Behaviour model of austenitic stainless steels for automotive structural parts, Steel Res. Int. 77 (2006) 686-691.

[65] S. Murugan, S.K. Rai, P. V. Kumar, T. Jayakumar, B. Raj, M.S.C. Bose, Temperature distribution and residual stresses due to multipass welding in type 304 stainless steel and low carbon steel weld pads, Int. J. Press. Vessel. Pip. 78 (2001) 307-317.

[66] P.J. Ferreira, P. Müllner, A thermodynamic model for the stacking-fault energy, Acta Mater. 46 (1998) 4479-4484. doi:10.1016/S1359-6454(98)00155-4.

[67] M. Olsson, Thermodynamic Modeling of the Stacking Fault Energy in Austenitic Stainless Steels, KTH Royal Institute of Technology, 2014. 

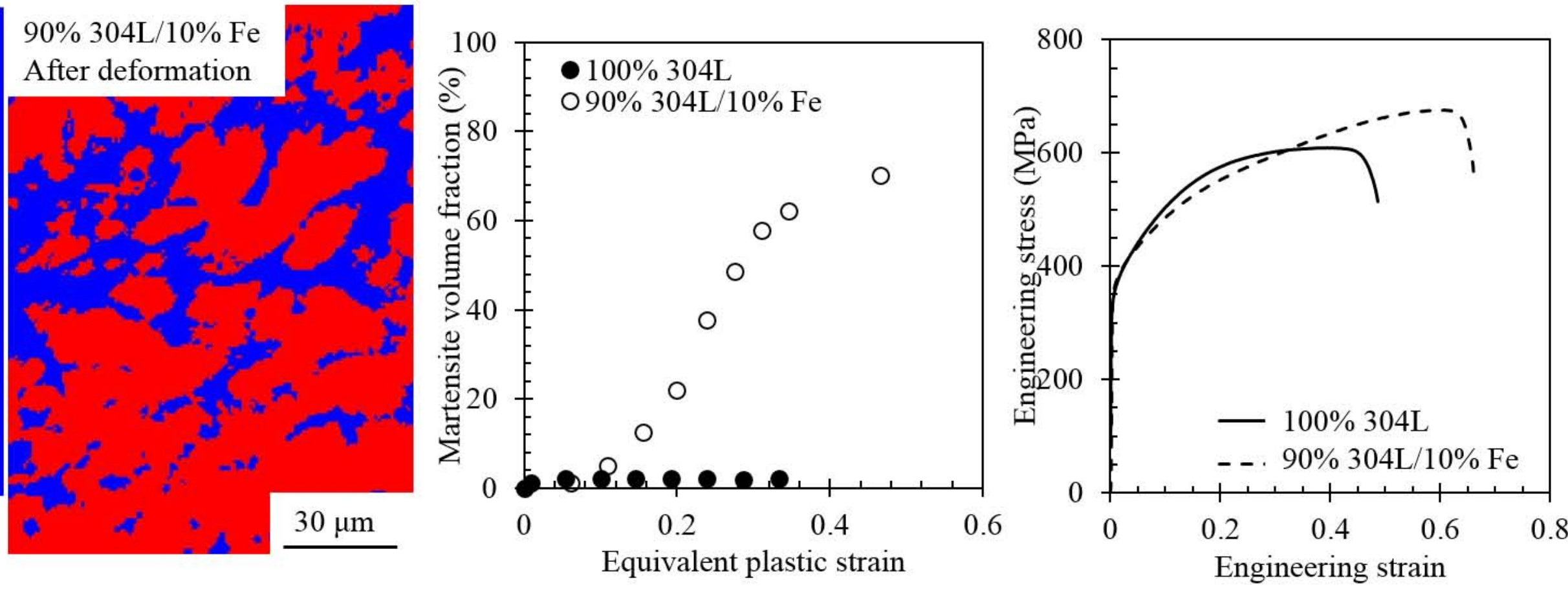

$30 \mu \mathrm{m}$

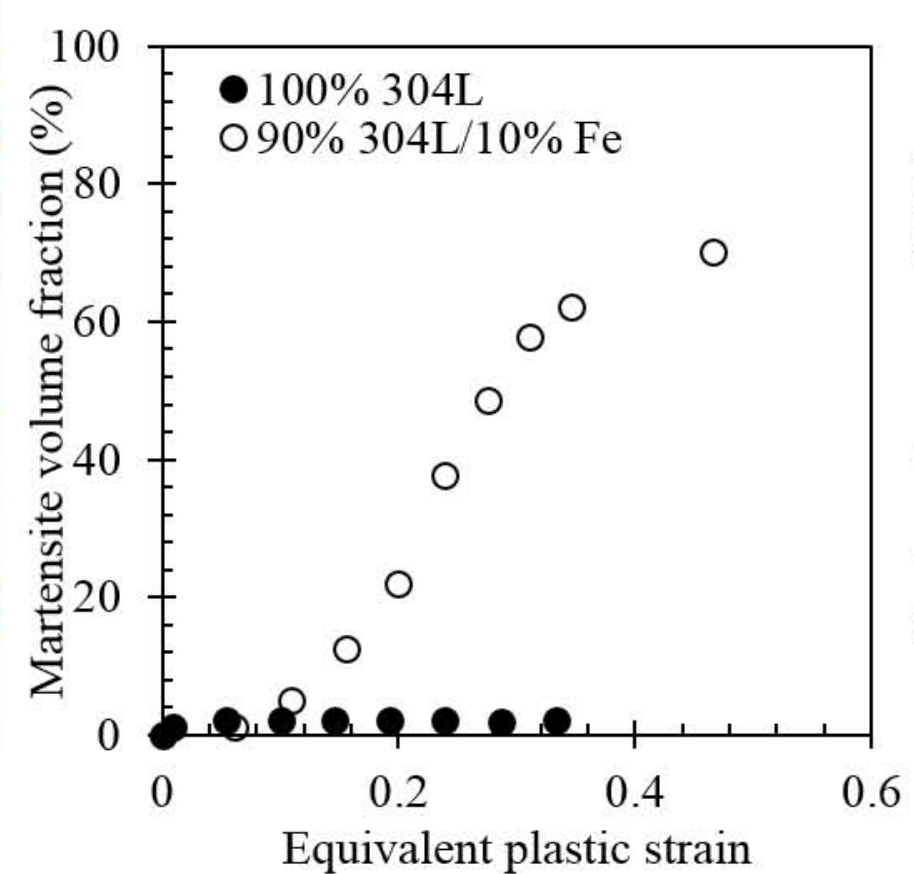

$100 \% 304 \mathrm{~L}$

O $90 \% 304 \mathrm{~L} / 10 \% \mathrm{Fe}$

- 